\title{
The Individual Poverty Incidence of Growth
}

\author{
Maria C. Lo Bue† and Flaviana Palmisano $\ddagger$ \\ $\dagger U N U-W I D E R$, Helsinki, 00530, Finland. (e-mail: Lobue@wider.unu.edu) \\ $\$$ Department of Economics and Law, Sapienza University of Rome, Via del Castro \\ Laurenziano 9, Rome,00161, Italy.(e-mail: flaviana.palmisano@uniroma1.it)
}

\begin{abstract}
The canonical approach to analyse the poverty impact of growth is based on the comparison of poverty before and after growth. Measurement tools endorsing this approach fail to capture the different experiences of poverty dynamic in the population: there can be groups of the population made poorer or non-poor made poor by growth. We propose an approach that allows measuring this individual poverty incidence of growth and show how it is related with existing models. We apply our framework to evaluate the poverty impact of growth in Indonesia, by comparing the 1993-2000 with the 2000-07 and 2007-14 growth spells.
\end{abstract}

\section{Introduction}

A highly debated issue in the economic literature concerns the evaluation of the distributional implications of growth and dates back to the Kuznets curve (the Kuznets hypothesis elaborated in 1955). This curve was used to understand the nature of the link between aggregate indicators of the distribution, such as the growth rate in mean income and the level of inequality. The increasing availability of survey data has more recently made the scientific community better aware that individuals, rather than a representative aggregate of the whole population, should be the focus of analysis for evaluating the impact of growth on the distribution (see, among others, Ravallion, 1998, 2012; Benjamin, et al., 2001; Ravallion and Chen, 2007). This individual-based perspective is now also central in the political agenda: for instance, one of the targets of the Sustainable Development Goals is to promote 'inclusive economic growth'- that is, growth that benefits all segments of society.

On the basis of this observation, a more recent literature has tried to go beyond the analysis of the nexus of aggregate indicators of the distribution and to understand whether and how each part of this distribution benefits from the overall growth process. This approach finds its roots in the so-called growth incidence curve (GIC) introduced by Ravallion and Chen (2003). The GIC plots the percentile-specific rate of income growth in a given period of time against each percentile. Different ways of aggregating each coordinate of the GIC 
produce different measures of growth pro-poorness: the extent to which poverty changes over time because of growth (see Kraay, 2006).

These criteria are based on the comparison of each income percentile at two different points in time. Therefore, although based on individual data, this procedure - built on the anonymity axiom (see inter alia Ravallion and Chen, 2003; Son, 2004; Essama-Nssah, 2005; Duclos, 2009; Essama-Nssah and Lambert, 2009) —ignores the individuals' identities and does not allow tracing their income dynamics. In terms of pro-poorness evaluation, this implies that, for a given initial distribution of income, if after growth the final distribution of income is exactly the same as the initial distribution of income except for the fact that there is complete re-ranking, this growth process would be judged to be neutral from a pro-poorness perspective. However, we might want to judge this process differently as, because of re-ranking, the poverty of each individual changes over time. The same counter-intuitive result is obtained when comparing this growth process to a process in which every individual maintains the same income and rank: the two growth processes would be judged to be identical from a pro-poorness perspective.

More recently, the literature has started to move from the study of the distribution of quintile-specific growth rates to the analysis of individual-specific growth rates and of individual transitions between two distributions. This has been done by relaxing the axiom of anonymity (see inter alia Grimm, 2007; Van Kerm, 2009; Bourguignon, 2011; Palmisano and Peragine, 2015; Jenkins and Van Kerm, 2016; Palmisano and Van de Gaer, 2016) with the conceptualization of non-anonymous GICs (na-GIC, or mobility profiles) introduced independently by Grimm (2007), Van Kerm (2009), and Bourguignon (2011). The na-GIC measures the individual-specific rate of economic growth between two points in time, thus plotting the income trajectories of all the individuals which were in the same initial position, independently of the position they acquire in the final distribution of income. To be more specific, the na-GIC is obtained by keeping the ranking of statistical units constant. Instead, comparing the initial and terminal quantile functions, as the standard GIC does, is equivalent to re-ranking individuals, with the result that it is not the income of the same individual that is compared, but the income of the same quantile.

Some recent contributions propose normative characterizations for the non-anonymous approach and hence provide a normative justification for the use of the na-GIC and a variety of aggregate measures based on these curves. ${ }^{1}$ However, with few exceptions that will be discussed below, no contribution has explicitly considered the extent to which economic growth hinders the upward income trajectories of the poorest segments of society. Hence, for instance, to measure the pro-poorness of growth, the poverty levels are computed in the two periods of time and then compared. If this procedure is valid when one is interested in measuring the pure distributional change that takes place, it can make a big difference if the poor people in the first period are still the same poor people in the following period, or if there has been a substantial reshuffling of the individual positions in the population. To capture this aspect, one needs to relax anonymity and account for each individual's poverty dynamics along the distribution. This information allows us to find out who are the winners and the losers from growth, useful data, for example, in the evaluation of the efficacy of policy reforms. For instance, in the case of a continuous monitoring of poverty dynamics,

${ }^{1}$ See also Barcena and Canto (2018) and Creedy and Gemmell (2018). 
the individuals that are poor before growth constitute the focus group of the assessment in the following periods.

Grimm (2007); Foster and Rothbaum (2016); Bresson, Duclos and Palmisano (2019) propose different ways to fill this gap. Grimm (2007); Bresson, Duclos and Palmisano (2019) provide aggregate measures of pro-poor growth in a non-anonymous fashion. Grimm (2007) proposes integrating the area under the na-GIC up to the initial headcount ratio $^{2}$ obtaining the variation over time of the Watt index of poverty ${ }^{3}$ for all the individuals who were poor in the first period. This measure, by focusing exclusively on the initially poor, does not inform on the income trajectories of those individuals who become poor during a given growth period. Bresson et al. (2019) propose comparing an aggregate measure of intertemporal poverty with aggregate poverty in the first period. Their measurement procedure, although incorporating the individual poverty dynamic into the aggregate measure of intertemporal growth, loses the individual-based perspective. Foster and Rothbaum (2016) introduce partial dominance conditions to make comparisons between growth processes according to their impact on poverty. Their framework keeps separate upward from downward mobility and the results are consistent with a specific class of poverty measures. Furthermore, all these contributions use the first period distribution as the reference period to identify individuals. Although this is usually considered to be a natural choice, it remains a purely arbitrary modelling choice. Different considerations motivate a generalization of these frameworks to allow for a more flexible assessment of the pro-poorness of growth. ${ }^{4}$

From a normative perspective, there is no prior on the relevance of the initially poor individuals with respect to the finally poor. There are reasons that justify the first period distribution as the reference one, such as the belief that poverty experienced earlier in life may impact the standard of living later in life, but not the other way around. But there are also reasons that justify the final-period distribution as the reference one. For instance, living with a low level of income may matter more the closer an individual is to the end of his or her life as the probability to improve the living standards tends to become smaller (see on this Hoy and Zheng, 2011). Looking at the income trajectories of the individuals who are poor in later stages of their lives is also relevant, considering the remarkable improvements in life expectancy and the growing elderly populations that many parts of the developing world have been witnessing.

In this work, we further explore the pro-poorness features of growth by proposing a framework, based on a non-anonymous approach, which maintains a strong focus on the mobility profiles of the poor. Standard non-anonymous approaches consider the incidence of growth on individual income dynamics. By setting to zero the change in income of the individuals who never experienced poverty, the tools proposed in this paper highlight, instead, two other important aspects of pro-poor growth. These are the income dynamics of the chronically poor and the transition into and out of poverty for those individuals who changed their poverty status. Thus, differently from previous contributions that have focused on the income dynamics of the distribution as a whole, thereby neglecting the

\footnotetext{
${ }^{2}$ The headcount ratio indicates the proportion of individuals in a given population whose resources, either income or consumption, are lower than the poverty line.

${ }^{3}$ The Watts index of poverty is the average across the population of poor individuals of the logarithmic distance between the poverty line and the income of each poor individual.

${ }^{4}$ See Palmisano (2018).
} 
individual poverty dynamics, and have considered the economic situation of individuals in the first period as the reference one (see Grimm, 2007; Bourguignon, 2011; Palmisano and Peragine, 2015; Jenkins and Van Kerm, 2016; Creedy and Gemmell, 2018; Palmisano 2018 ), this is the first paper that provides a normatively grounded measurement framework that focuses on the poverty status evolution of individuals, robustly to the choice of specific functions used to evaluate growth pro-poorness and to the reference period used to identify individuals.

Interestingly, our dominance conditions can be interpreted in some cases as a censored version of the na-GIC framework dominance, and in some others as "pro-poor growth curves'. Thus, we provide normative support for the use of these two tools to make propoorness judgements. Our framework represents an additional and complementary tool that researchers may employ in their attempt to grasp the different facets of growth propoorness.

We then apply our measurement model to the Indonesian setting in order to evaluate to what extent the remarkable improvements this country has made in economic growth over the last two decades have favoured poverty reduction and exit for the most disadvantaged segments of Indonesian society. To the best of or knowledge, this is the first paper that analyses this specific feature of the Indonesian income distribution, as previous contributions were mostly concerned on the evolution of aggregate poverty thereby ignoring the poverty evolution of each segment of the society (see, Timmer, 2018). More specifically, by comparing three different growth spells (1993-2000, 2000-07, and 2007-14), we show that whereas growth in the 1990s brought the largest transitions out of poverty for the initially poorer, the two more recent periods have been less pro-poor. Yet, when considering the poverty incidence of growth for the finally poor, we observe that the most recent period has not performed differently from the first one. This not-unambiguous finding for the 2007-14 period points to increasing mobility possibilities for the Indonesian lower-middle income class, but at the same time to the very little progress the country has recently made to reduce vulnerability to poverty.

Hence, this paper makes two contributions to the literature. The first is theoretical as the paper introduces new tools to compare the distributional implications of growth. The second contribution is empirical, as it provides new evidence on the mobility patterns-over the last two decades-of the chronically and transitory poor in Indonesia and on the effect of growth on intertemporal poverty.

The rest of the paper is organized as follows. Section II provides the theoretical framework. Section III provides an empirical illustration based on longitudinal survey data from Indonesia. Section IV concludes.

\section{Theoretical framework}

\section{Notation and properties}

Let a distribution of income at time $t$ be represented by its cumulative distribution function (CDF) $F\left(y_{t}\right) ; F\left(y_{t}\right)=P\left(\tilde{y}_{t} \in \Re_{+}: \tilde{y}_{t} \leqslant y_{t}\right)$, that is the CDF returns the probability $p \in[0,1]$ of observing income $y_{t}$ less than $\tilde{y}_{t}$ in that society in period $t$. We are interested in understanding the dynamic of the poverty of individuals in a given society. In particular, our aim is to 
compare the pro-poorness of different growth processes - that is, the extent to which growth reduces (or increases) poverty, according to an extended non-anonymous individual-based perspective. Therefore, we need to keep track of the identity of individuals, where such identity is represented by their rank in the initial and final distribution of income. For this reason, let the inverse of this CDF be denoted by $y_{t}\left(p_{t}\right)$, where $y_{t}\left(p_{t}\right)=\inf \left\{y_{t} \in \Re_{+} \mid F\left(y_{t}\right) \geqslant\right.$ $\left.p_{t}\right\}$. Hence, $y_{t}\left(p_{t}\right):[0,1] \rightarrow \Re_{+}$represents the income of the person whose rank in the distribution $F\left(y_{t}\right)$ is $p_{t} . p_{t}$ then represents the rank-or identity-of a given person in $t$. Similarly, we let $F\left(y_{t+1}\right)$ denote the CDF of the final distribution of income. Following the same line of reasoning as before, $p_{t+1}$ then represents the rank-or identity - of a given person in $t+1$.

Assume that poverty at the individual level is measured by the poverty gap, denoted by $\pi(y, z)$, either relative (i.e. $\left.\frac{z-y}{z}\right)$ or absolute (i.e. $z-y$ ), which is a standard assumption in the poverty measurement literature (see Zheng, 1997 for an excellent review), where $z$ is the poverty line and $y$ is the income of a poor individual. Of course, $\pi(y, z)=0$ if $y \geqslant z$ and $\pi(y, z)>0$ if $y<z$. We denote by $\delta\left(p_{t}, z\right)$ the extent of poverty reduction in moving from date $t$ to $t+1$ for a given individual ranked $p$ in the initial period, and by $\delta\left(p_{t+1}, z\right)$ the extent of poverty reduction (increase) in moving from date $t$ to $t+1$ for a given individual ranked $p$ in the final period; $\delta$ can either measure an absolute reduction (increase) $-\pi\left(y_{t}\left(p_{t}\right), z\right)-$ $\pi\left(y_{t+1}\left(p_{t}\right), z\right)$-or a relative poverty reduction (increase) $-\frac{\pi\left(y_{t}\left(p_{t}\right), z\right)-\pi\left(y_{t+1}\left(p_{t}\right), z\right)}{\pi\left(y_{t}\left(p_{t}\right), z\right)}$. We then denote by $G^{(t, t+1)}$ the growth process taking place between $t$ and $t+1$ that gives rise to a given combination of each individual's initial and final poverty level. We are interested in judging $G^{(t, t+1)}$ from a normative and pro-poorness perspective. We propose that social preferences over a growth process can be represented by the following Social Evaluation Function (SEF, hereafter) which is a generalization of the rank-dependent SEF proposed by Yaari (1988) and is based on an additive aggregation of each individual's poverty reduction over time:

$$
\hat{W}\left(G^{(t, t+1)}\right)=\frac{1}{2}\left(\int_{0}^{1}\left(v\left(p_{t}\right) \delta\left(p_{t}, z\right) d p_{t}+\int_{0}^{1} v\left(p_{t+1}\right) \delta\left(p_{t+1}, z\right) d p_{t+1}\right)\right)
$$

Thus, a social evaluation of growth pro-poorness is obtained as the average of the initial- and final-period sensitive poverty dynamic. The first component of equation (1), $\int_{0}^{1} v\left(p_{t}\right) \delta\left(p_{t}, z\right) d p_{t}$, is a weighted sum of the extent of poverty reduction experienced by the individuals that are identified according to their rank in the initial period; $v\left(p_{t}\right)$ is the social weight function which depends on the rank of individuals in the initial distribution of income. The second component, $\int_{0}^{1} v\left(p_{t+1}\right) \delta\left(p_{t+1}, z\right) d p_{t+1}$, is a weighted sum of the extent of poverty reduction experienced by the individuals that are identified on the basis of their rank in the final period; $v\left(p_{t+1}\right)$ is the social weight function which depends on the rank of individuals in the final distribution of income.

Note that both components of equation (1) can be interpreted as the change over time of a non-anonymous and rank-dependent aggregate measure of poverty. For instance, the first component could also be written as: $\int_{0}^{1} v\left(p_{t}\right) \pi\left(y_{t+1}\left(p_{t}\right), z\right) d p_{t}-\int_{0}^{1} v\left(p_{t}\right) \pi\left(y_{t}\left(p_{t}\right), z\right) d p_{t}$, where the first term is a standard measure of rank-dependent poverty in the initial period (see Shorrocks, 1995), while the second term is an aggregate non-anonymous rank-dependent measure of poverty in the final period: it is non-anonymous because the weights depend 
on the rank of individuals in the initial period and not in the final one. That is, we assume that we can identify individuals not only by their level of postgrowth income, but also by their rank in the initial distribution of income.

Clearly, the assessment of the pro-poorness features of a growth process is an exercise in the social evaluation context. Different preferences over growth pro-poorness can be expressed through our model imposing different restrictions on the social weights, hence selecting different classes of weight profiles. These, in turn, define different classes of SEF of growth pro-poorness.

The first restriction we impose, Property 1, reflects a standard monotonicity assumption.

Property 1. (Poverty-reducing growth). $v\left(p_{t}\right) \geqslant 0$ and $v\left(p_{t+1}\right) \geqslant 0$ for all $p_{t}, p_{t+1} \in[0,1]$.

This implies that, all else being equal, an experience of poverty reduction at the individual level will not decrease $\hat{W}\left(G^{(t, t+1)}\right)$, whereas an experience of poverty increase will not increase it. The marginal impact will instead be the same. A reduction in poverty equal to $\delta$ experienced by an individual ranked $p_{t}$ will result in an increase of $\hat{W}\left(G^{(t, t+1)}\right)$ equal to $v\left(p_{t}\right)^{*} \delta$, while an increase in poverty of $\delta$ experienced by the same individual will result in a reduction of $\hat{W}\left(G^{(t, t+1)}\right)$ equal to $v\left(p_{t}\right)^{*} \delta .^{5}$

The second property we consider makes our SEF distribution-sensitive.

Property 2. (Poorer-preferring growth). $\frac{\delta v\left(p_{t}\right)}{\delta p_{t}} \leqslant 0$ and $\frac{\delta v\left(p_{t+1}\right)}{\delta p_{t+1}} \leqslant 0$ for all $p_{t}, p_{t+1} \in[0,1]$.

This property requires that the first derivative of the social weight function $v\left(p_{t}\right)$ with respect to $p_{t}$ and of $v\left(p_{t+1}\right)$ with respect to $p_{t+1}$ is non-positive. Therefore, the weighting function decreases with the rank of individuals, respectively, in the initial and final distributions. Increasing by a given amount the poverty reduction of an initially (finally) poor individual and decreasing by the same amount the poverty reduction of an initially (finally) less-poor individual will not decrease $\hat{W}\left(G^{(t, t+1)}\right)$. An individual's poverty reduction increases more the social evaluation of growth the poorer is the individual in the initial (final) distribution. In the same vein, an individual's poverty increment decreases more the social evaluation of pro-poorness the poorer in the initial (final) distribution is the individual experiencing that reduction.

Properties 1 and 2 are relevant in the context of our paper as they account for the identity of individuals in both the pregrowth and postgrowth distributions. They do not discriminate between being poor before growth and being poor after growth.

The next two properties refine Property 2, allowing for situations in which a social planner would either prefer the initial period status over the final one or the other way round.

\section{Property 3. (Initially poorer-preferring growth). $\quad \frac{\delta v\left(p_{t}\right)}{\delta p_{t}} \leqslant \frac{\delta v\left(p_{t+1}\right)}{\delta p_{t+1}} \leqslant 0$ for all $p_{t}, p_{t+1} \in$ $[0,1]$.}

Property 3 reflects the idea that the status of individuals in the first period matters more than in the second period. In other words, a social planner would give more weight to the poorer-preferring growth in the initial period than to the poorer-preferring growth in the

\footnotetext{
${ }^{5}$ Equivalently, poverty reduction equal to $\delta$ experienced by an individual ranked $p_{t+1}$ will result in an increase of $\hat{W}\left(G^{(t, t+1)}\right)$ equal to $v\left(p_{t+1}\right) * \delta$, while an increase in poverty of $\delta$ experienced by the same individual will result in a reduction of $\hat{W}\left(G^{(t, t+1)}\right)$ equal to $v\left(p_{t+1}\right) * \delta$.
} 
final period. According to this property, $\hat{W}\left(G^{(t, t+1)}\right)$ results in being more sensitive to the poverty incidence of growth when this incidence is evaluated by looking at the rank of individuals in the initial distribution of income than to the poverty incidence of growth when this incidence is evaluated by looking at the rank of individuals in the final distribution of income. That is, a social planner endorsing these preferences would prioritize a transfer of poverty reduction from an initially less-poor individual to an initially poorer individual over the same transfer determined by the rank of individuals in the final distribution of income. This property endorses the view that poverty experienced in the earlier stages of life matters more than poverty experienced later on.

An opposite argument is, instead, at the base of the next property.

$$
\text { Property 4. (Final poorer-preferring growth). } \frac{\delta v\left(p_{t+1}\right)}{\delta p_{t+1}} \leqslant \frac{\delta v\left(p_{t}\right)}{\delta p_{t}} \leqslant 0 \text { for all } p_{t}, p_{t+1} \in[0,1] .
$$

According to Property 4, a social planner would prioritize a progressive transfer of poverty reduction from a finally less-poor individual to a finally poorer individual to the same transfer between individuals identified on the base of their rank in the initial distribution of income. Therefore, this property makes the SEF more sensitive to the relative status of poor individuals in the final period than their status in the initial period. This property is based on the assumption that poverty matters more the closer a person is to the end of his or her life.

The following families of SEFs can then be identified:

- $\hat{\mathbf{W}}_{1}$ is the class of SEFs constructed as in equation (1) and with social weight functions satisfying Property 1.

- $\hat{\mathbf{W}}_{1,2}$ is the class of SEFs constructed as in equation (1) and with social weight functions satisfying Properties 1 and 2.

- $\hat{\mathbf{W}}_{1,3}$ is the class of SEFs constructed as in equation (1) and with social weight functions satisfying Properties 1 and 3.

- $\hat{\mathbf{W}}_{1,4}$ is the class of SEFs constructed as in equation (1) and with social weight functions satisfying Properties 1 and 4.

Before illustrating the results, it is useful to introduce the following definitions:

Definition 1. Absolute and relative censored ex ante na-GIC, $g\left(y\left(p_{t}\right), z\right)$, where $g\left(y\left(p_{t}\right), z\right)$ is $\min \left\{y_{t+1}\left(p_{t}\right), z\right\}-\min \left\{y_{t}\left(p_{t}\right), z\right\} \forall p_{t}$ if absolute and $\frac{\min \left\{y_{t+1}\left(p_{t}\right), z\right\}-\min \left\{y_{t}\left(p_{t}\right), z\right\}}{\min \left\{y_{t}\left(p_{t}\right), z\right\}} \forall p_{t}$ if relative.

The curve introduced in Definition 1 is a censored version of the na-GIC, either absolute or relative. This means that to build up this curve, one has to compare the income of every individual before and after growth, where this income is censored at the poverty line and individuals are sorted according to their rank in the pregrowth distribution of income. It follows that if individuals are poor in both periods, then the censored na-GIC is equivalent to the standard na-GIC. A positive curve means that an individual is experiencing a reduction in or an exit from poverty. The other way round, a negative curve means that the individual is experiencing an increase in or a fall into poverty. 
Definition 2. Absolute and relative censored ex post na-GIC, $g\left(y\left(p_{t+1}\right), z\right)$, where $g\left(y\left(p_{t+1}\right), z\right)$ is $\min \left\{y_{t+1}\left(p_{t+1}\right), z\right\}-\min \left\{y_{t}\left(p_{t+1}\right), z\right\} \forall p_{t+1}$ if absolute and $\frac{\min \left\{y_{t+1}\left(p_{t+1}\right), z\right\}-\min \left\{y_{t}\left(p_{t+1}\right), z\right\}}{\min \left\{y_{t}\left(p_{t+1}\right), z\right\}} \forall p_{t+1}$ if relative.

The curve introduced in Definition 2 is identical to the curve introduced in Definition 1, with the only exception that individuals are now identified and sorted according to their rank in the final distribution of income.

\section{Results}

We are now ready to illustrate our results. All proofs are gathered in Appendix A.

Proposition 1. Given two growth processes $G_{A}^{(t, t+1)}$ and $G_{B}^{(t, t+1)}, G_{A}^{(t, t+1)}$ is said to be more pro-poor than $G_{B}^{(t, t+1)} \forall \hat{W} \in \hat{\mathbf{W}}_{1}$ if and only if for a given poverty line $\mathrm{z}$

$$
\text { (i) } g_{A}\left(y\left(p_{t}\right), z\right) \geqslant g_{B}\left(y\left(p_{t}\right), z\right) \forall p_{t} \in[0,1]
$$

and

$$
\text { (ii) } g_{A}\left(y\left(p_{t+1}\right), z\right) \geqslant g_{B}\left(y\left(p_{t+1}\right), z\right) ; \forall p_{t+1} \in[0,1]
$$

with $g\left(y\left(p_{t}\right), z\right)$ and $g\left(y\left(p_{t+1}\right), z\right)$ being relative if $\delta\left(p_{t}, z\right)$ and $\delta\left(p_{t+1}, z\right)$ are assumed to be relative and absolute otherwise.

Proposition 1 characterizes two dominance conditions of the first order. The first condition requires checking the censored ex ante na-GIC dominance for every percentile of the income distribution. That is, the distribution of individuals' censored income change of growth process $A$ must lie nowhere below that of $B$, for all the initial-income ranks. The second condition requires checking the dominance between two censored ex post na-GIC; that is, to check that the distribution of individuals' censored income change of growth process $A$ must lie nowhere below that of $B$ for all the final-income ranks. Hence, when we only impose poverty-reducing growth, to determine which growth process is preferable in terms of pro-poorness, we need to check that for each rank of the initial and final period the poverty reduction experienced is higher in $A$ than in $B$.

Two special cases of Proposition 1 are worth mentioning:

Corollary 1. Given two alternative growth processes, $G_{A}^{(t, t+1)}$ and $G_{B}^{(t, t+1)}, G_{A}^{(t, t+1)}$ is said to be more pro-poor than $G_{B}^{(t, t+1)} \forall \hat{W} \in \hat{\mathbf{W}}_{1}$ such that $v\left(p_{t+1}\right)=0$ if and only if

$$
g_{A}\left(y\left(p_{t}\right), z\right) \geqslant g_{B}\left(y\left(p_{t}\right), z\right) \forall p_{t} \in[0,1]
$$

with $g\left(y\left(p_{t}\right), z\right)$ and $g\left(y\left(p_{t+1}\right), z\right)$ being relative if $\delta\left(p_{t}, z\right)$ and $\delta\left(p_{t+1}, z\right)$ are assumed to be relative and absolute otherwise.

Corollary 2. Given two alternative growth processes, $G_{A}^{(t, t+1)}$ and $G_{B}^{(t, t+1)}, G_{A}^{(t, t+1)}$ is said to be more pro-poor than $G_{B}^{(t, t+1)} \forall \hat{W} \in \hat{\mathbf{W}}_{1}$ such that $v\left(p_{t}\right)=0$ if and only if

$$
g_{A}\left(y\left(p_{t+1}\right), z\right) \geqslant g_{B}\left(y\left(p_{t+1}\right), z\right) \forall p_{t+1} \in[0,1]
$$

with $g\left(y\left(p_{t}\right), z\right)$ and $g\left(y\left(p_{t+1}\right), z\right)$ being relative if $\delta\left(p_{t}, z\right)$ and $\delta\left(p_{t+1}, z\right)$ are assumed to be relative and absolute otherwise. 
In Corollary 1, we assume that only the identity of individuals in the first period is relevant to pro-poorness evaluations. The resulting dominance condition is the only one and corresponds to the censored ex ante na-GIC dominance. The other way round, in Corollary 2, only the identity of individuals in the final period matters and the resulting pro-poorness test is represented by the dominance of the censored ex post na-GIC.

We now consider the class of SEFs $\hat{\mathbf{W}}_{1,2}$, for which the following result holds.

Proposition 2. Given two growth processes $G_{A}^{(t, t+1)}$ and $G_{B}^{(t, t+1)}, G_{A}^{(t, t+1)}$ is said to be more pro-poor than $G_{B}^{(t, t+1)} \forall \hat{W} \in \mathbf{W}_{1,2}$ and for a given poverty line $\mathrm{z}$ if and only if

(i) $\int_{0}^{p_{t}} g_{A}\left(y\left(q_{t}\right), z\right) d q_{t} \geqslant \int_{0}^{p_{t}} g_{B}\left(y\left(q_{t}\right), z\right) d q_{t} \forall p_{t} \in[0,1] \forall p_{t} \in[0,1]$

and

$$
\text { (ii) } \int_{0}^{p_{t+1}} g_{A}\left(y\left(q_{t+1}\right), z\right) d q_{t+1} \geqslant \int_{0}^{p_{t+1}} g_{B}\left(y\left(q_{t+1}\right), z\right) d q_{t+1} \forall p_{t+1} \in[0,1]
$$

with $g\left(y\left(p_{t}\right), z\right)$ and $g\left(y\left(p_{t+1}\right), z\right)$ being relative if $\delta\left(p_{t}, z\right)$ and $\delta\left(p_{t+1}, z\right)$ are assumed to be relative, and absolute otherwise.

Two conditions of the second order are characterized by this proposition. According to the first condition, we have to order increasingly individuals on the basis of their rank in the initial distribution and check that the cumulated censored na-GIC is higher in $A$ than in $B$ at every $p_{t}$. According to the second condition, we have to order increasingly individuals on the basis of their rank in the final distribution and check that the cumulated censored income change is higher in $A$ than in $B$ at every $p_{t+1}$. If both conditions are satisfied, growth can be said to be more pro-poor in the dominating process than in the dominated one. That is, the poverty reduction differential between initially poorer and less-poor individuals is more favourable for the initially poorer, and the poverty reduction differential between finally poorer and less-poor individuals is more favourable to the finally poorer in the dominating process than in the dominated one.

Special cases of Proposition 2 are gathered in the following two corollaries.

Corollary 3. Given two growth processes $G_{A}^{(t, t+1)}$ and $G_{B}^{(t, t+1)}, G_{A}^{(t, t+1)}$ is said to be more pro-poor that $G_{B}^{(t, t+1)} \forall \hat{W} \in \mathbf{W}_{1,2}$ and for a given poverty line z such that $\frac{\delta v\left(p_{t+1}\right)}{\delta p_{t+1}}=0$ for all $p_{t+1} \in[0,1]$ if and only if

$$
\int_{0}^{p_{t}} g_{A}\left(y\left(q_{t}\right), z\right) d q_{t} \geqslant \int_{0}^{p_{t}} g_{B}\left(y\left(q_{t}\right), z\right) d q_{t} \forall p_{t} \in[0,1]
$$

with $g\left(y\left(p_{t}\right), z\right)$ and $g\left(y\left(p_{t+1}\right), z\right)$ being relative if $\delta\left(p_{t}, z\right)$ and $\delta\left(p_{t+1}, z\right)$ are assumed to be relative and absolute otherwise.

Corollary 4. Given two growth processes $G_{A}^{(t, t+1)}$ and $G_{B}^{(t, t+1)}, G_{A}^{(t, t+1)}$ is said to be more pro-poor than $G_{B}^{(t, t+1)} \forall \hat{W} \in \mathbf{W}_{1,2}$ and for a given poverty line $\mathrm{z}$ such that $\frac{\delta v\left(p_{t}\right)}{\delta p_{t}}=0$ for all $p_{t} \in[0,1]$ if and only if

$$
\int_{0}^{p_{t+1}} g_{A}\left(y\left(q_{t+1}\right), z\right) d q_{t+1} \geqslant \int_{0}^{p_{t+1}} g_{B}\left(y\left(q_{t+1}\right), z\right) d q_{t+1} \forall p_{t+1} \in[0,1] \forall p_{t+1} \in[0,1]
$$


with $g\left(y\left(p_{t}\right), z\right)$ and $g\left(y\left(p_{t+1}\right), z\right)$ being relative if $\delta\left(p_{t}, z\right)$ and $\delta\left(p_{t+1}, z\right)$ are assumed to be relative and absolute otherwise.

Corollaries 3 and 4 account only for the identity of individuals, respectively, in the first and final period distribution. Therefore, Corollary 3 only requires the test of condition (i) of Proposition 2-that is, the check of the censored cumulated ex ante na-GIC dominance. Corollary 4 only requires the test of condition (ii) of Proposition 2 - that is the check of the censored cumulated ex post na-GIC dominance.

One might be willing to discriminate between first- and second-period distribution as the reference one to identify individuals. In particular, if it is believed that the rank before growth matters more than the rank after growth, we get the following result.

Proposition 3. Given two growth processes $G_{A}^{(t, t+1)}$ and $G_{B}^{(t, t+1)}, G_{A}^{(t, t+1)}$ is said to be more pro-poor than $G_{B}^{(t, t+1)} \forall \hat{W} \in \mathbf{W}_{1,3}$ and for a given poverty line $\mathrm{z}$ if and only if

$$
\text { (i) } \int_{0}^{p_{t}} g_{A}\left(y\left(q_{t}\right), z\right) d q_{t} \geqslant \int_{0}^{p_{t}} g_{B}\left(y\left(q_{t}\right), z\right) d q_{t} \forall p_{t} \in[0,1] \forall p_{t} \in[0,1]
$$

and

$$
\text { (ii) } \sum_{t=1}^{T} \int_{0}^{p_{t}} g_{A}\left(y\left(q_{t}\right), z\right) d q_{t} \geqslant \sum_{t=1}^{T} \int_{0}^{p_{t}} g_{B}\left(y\left(q_{t}\right), z\right) d q_{t} \forall p_{t} \in[0,1] \forall p_{t} \in[0,1]
$$

with $g\left(y\left(p_{t}\right), z\right)$ and $g\left(y\left(p_{t+1}\right), z\right)$ being relative if $\delta\left(p_{t}, z\right)$ and $\delta\left(p_{t+1}, z\right)$ are assumed to be relative and absolute otherwise.

Proposition 3 characterizes a sequential dominance condition of the second order. In fact, condition (i) is the first step of this sequential dominance and requires that the cumulative censored na-GIC be higher in $A$ than in $B$ at all ranks of the initial distribution - that is, at all $p_{t}$. This first step is equivalent to condition (i) in Proposition 2. Condition (ii) is the second and, in this specific case, the last step of this sequential dominance, given that $T=2$. It requires that the sum of the cumulative censored na-GIC between the initial and final period is higher in $A$ than in $B$ for all ranks $p \in[0,1]$. From a procedural point of view, we have to merge the cumulative distribution of individual censored income changes with individuals ordered on the basis of the initial income to that of individual censored income changes with individuals ordered on the basis of the final income. The merging takes place by summing at every $p$ the cumulative growth up to the individual ranked $p$ in the initial period to the cumulative growth of individuals ranked $p$ in the final period. We then have to check that the sum between the cumulative censored growth of individuals ranked $p$ in $t$ and the cumulative censored growth of individuals ranked $p$ in $t+1$ is higher in $A$ than in $B$ and this dominance must be checked at every $p \in[0,1]$.

Last, if it is believed that the rank after growth matters more than the rank before growth, we get the following result.

Proposition 4. Given two growth processes $G_{A}^{(t, t+1)}$ and $G_{B}^{(t, t+1)}, G_{A}^{(t, t+1)}$ is said to be more pro-poor than $G_{B}^{(t, t+1)} \forall \hat{W} \in \mathbf{W}_{1,4}$ and for a given poverty line $\mathrm{z}$ if and only if

$$
\text { (i) } \int_{0}^{p_{t+1}} g_{A}\left(y\left(q_{t+1}\right), z\right) d q_{t+1} \geqslant \int_{0}^{p_{t+1}} g_{B}\left(y\left(q_{t+1}\right), z\right) d q_{t+1} \forall p_{t+1} \in[0,1]
$$


and

$$
\text { (ii) } \sum_{t=1}^{T} \int_{0}^{p_{t}} g_{A}\left(y\left(q_{t}\right), z\right) d q_{t} \geqslant \sum_{t=1}^{T} \int_{0}^{p_{t}} g_{B}\left(y\left(q_{t}\right), z\right) d q_{t} \forall p_{t} \in[0,1]
$$

with $g\left(y\left(p_{t}\right), z\right)$ and $g\left(y\left(p_{t+1}\right), z\right)$ being relative if $\delta\left(p_{t}, z\right)$ and $\delta\left(p_{t+1}, z\right)$ are assumed to be relative and absolute otherwise.

Proposition 4 characterizes a downward sequential dominance condition of the second order. Condition (i) is the first step of this sequential dominance and requires that the cumulative censored growth be higher in $A$ than in $B$ at all ranks of the final distribution. It is equivalent to condition (ii) in Proposition 2. Condition (ii) is the second and last step of this sequential dominance and is equivalent to condition (ii) of Proposition 3.

The difference between Propositions 3 and 4 is clear. According to the former, the dominance of $A$ over $B$ is checked starting from a distribution of individual censored income changes, in which individuals are ordered on the basis of the first-period rank. According to the latter, we have to start from a distribution of individual censored income changes in which individuals are ordered on the basis of the final period rank. ${ }^{6}$

\section{Aggregate measures}

It is possible to derive a family of aggregate measures of pro-poorness by imposing more restrictions on the social weights. This procedure might be helpful in all those cases in which the tests introduced and discussed above do not allow us to compare growth processes because of the crossing of the curves in one or more points of the distribution. We propose the following family of aggregate measures of growth:

$$
\tilde{W}\left(G^{(t, t+1)}\right)=\frac{1}{T} \sum_{t=1}^{T} \int_{0}^{1} \omega_{t}\left(1-p_{t}\right)^{\omega_{t}-1} \delta\left(p_{t}, z\right) d p_{t}
$$

The expression of the social weights takes its inspiration from the generalized Gini coefficient (Donaldson and Weymark, 1980, 1983; Weymark, 1981; Yitzhaki, 1983). ${ }^{7}$

In particular, imposing $\omega_{t}=\omega_{t+1}=2$, which corresponds to the standard Gini weight, we obtain an index of pro-poor growth. This is an aggregate index based on an SEF endorsing preferences for monotonicity and pro-poorness of growth, thus satisfying Properties 1 and 2 , and that gives equal relevance to the status of individuals in both the initial and final periods. This index attaches to each $\delta(p)$ a weight that decreases with the rank of the individual in the initial and final income distributions. This measure can be used to compare different growth processes on the basis of their ability to reduce poverty from one period to the other and favour the income change of the most disadvantaged individuals as compared to those with most advantage.

By imposing $\omega_{t}=3$ and $\omega_{t+1}=2$, we obtain a preference for the initial-period index. This second index can be used if Proposition 3 is not able to guarantee a ranking. This

\footnotetext{
${ }^{6}$ See Appendix B for some generalizations of these results.

${ }^{7}$ See Palmisano and Peragine (2015); Jenkins and Van Kerm (2016); Palmisano and Van de Gaer (2016) for application of this weight in the context of growth evaluation.
} 
index reflects the preferences of a social planner that regrets income reductions from one period to the other, prefers growth processes that benefit poorer individuals more than richer individuals, and cares more about the relative status of individuals in the initial period than their status in the final period.

Last, by imposing $\omega_{t}=2$ and $=\omega_{t+1}=3$, we obtain a preference for the final-period index that can be used if Proposition 4 is not able to guarantee a ranking. Differently from the previous index, it reflects the preference of a social planner that cares more about the relative status of individuals in the final period than the status in the initial period.

\section{An application to Indonesia}

\section{Data}

The data used in our empirical analysis are extracted from the second, third, fourth and fifth waves of the Indonesia Family Life Survey (IFLS). This is one of the largest longitudinal developing country survey datasets and it tracks, with high follow-up rates, individuals and households in 13 Indonesian provinces located in the islands of Sumatra, Java, Kalimantan, Sulawesi, Bali and West Nusa Tenggara (Strauss, Witoelar and Sikoki, 2016). The main variable needed for our empirical illustration is a flow measure of well-being, which in a developing country context is better proxied by per capita expenditure. Real values in Indonesian rupiahs $(\mathrm{Rp})$ are computed by deflating both temporally and spatially with reference to Jakarta prices in 2002. ${ }^{8}$

A selection of key summary statistics is presented in Table C1 in Appendix C. As can be seen, Indonesia's sustained consumption growth reflects substantial reductions in monetary poverty, as shown by the declining trend in the share of the chronically poor (i.e. individuals living below the poverty line in both periods). At the same time in all the periods considered, our data reveal a strong pattern of individual upward and downward mobility.

\section{Results}

Our first illustration is related to the comparison of the three growth periods (1993-2000 vs $2000-07$ vs 2007-14) in Indonesia.

We start by estimating the standard na-GIC framework according to both the ex ante and ex post approach. These curves are plotted in Figures 1 and 2. Despite the presence of some crossing points between the three curves, they are quite informative about the worst performance of the growth episode that took place in the first half of 2000s (2000-07) relatively to the previous one (1993-00) and the most recent one (2007-14). Especially looking at the cumulative version of these curves, a clear dominance can always be established between the three episodes according to both ex ante and ex post approaches. Hence, when standard na-GICs are considered, the first and last spells dominate the intermediate

\footnotetext{
${ }^{8}$ To deflate values temporally and spatially, first the sum of the urban and rural poverty lines in each province was converted to real values using the consumer price index (base year 2002). Then, the ratio of the poverty line of each province to the poverty line in Jakarta was applied as our spatial deflator. Data on the regional urban and rural poverty lines and on the CPI are sourced from Badan Pusat Statistik (BPS), Indonesia's central statistical agency.
} 

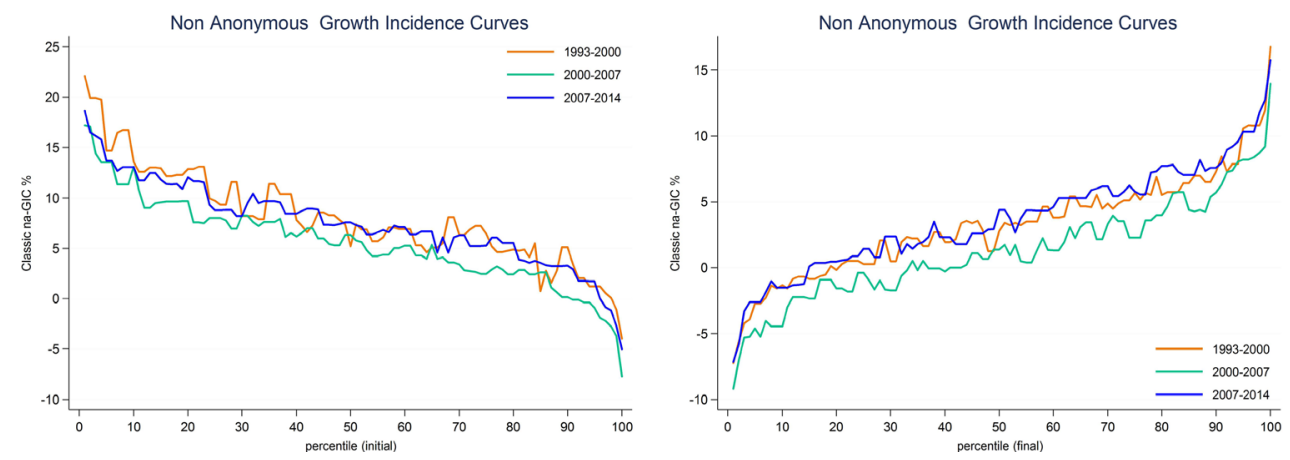

Figure 1. Non-anonymous GICs: ex ante (left) and ex post (right) approaches Source: Authors' elaboration based on IFLS1, IFLS2, IFLS3, IFLS4 and IFLS5
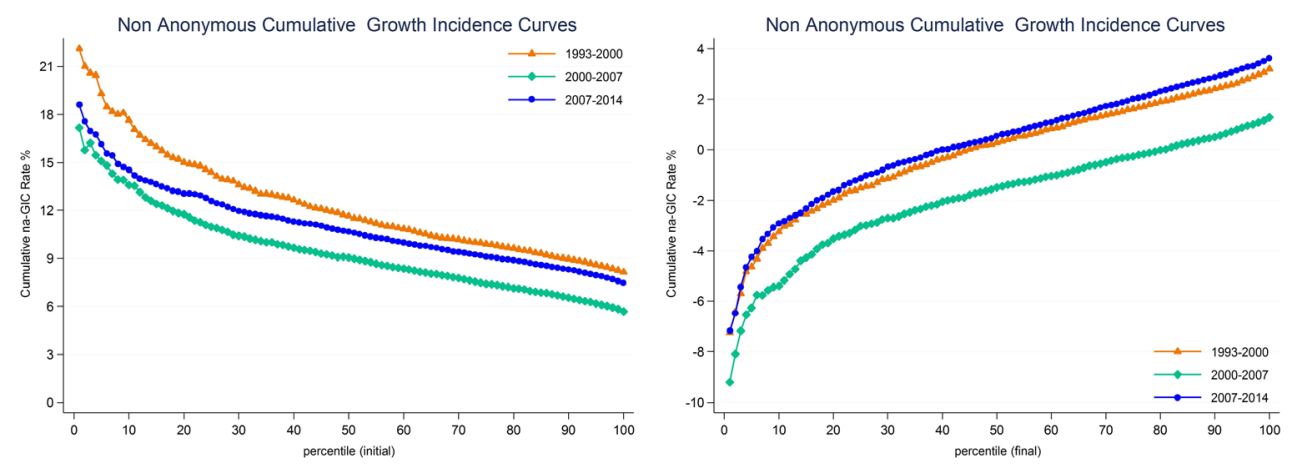

Figure 2. Cumulative non-anonymous GICs: ex ante (left) and ex post (right) approaches

Source: Authors' elaboration based on IFLS1, IFLS2, IFLS3, IFLS4 and IFLS5

spell and this dominance is robust to whether individuals' status in the initial or final period is considered (see Figure 2).

In order to investigate whether focusing on the dynamics of individuals' poverty, instead of income, does make a difference in the evaluation of the incidence of growth, we now test the first-order censored na-GIC dominance, which consists of comparing the censored growth rate at each percentile of the distribution, conditional on the rank in the initial period in one case (ex ante) and on the rank in the final period in the other (ex post). These conditions are plotted in Figure 3. As one would expect, because of the stringency that they impose, no dominance can be defined between the growth spells under investigation as the respective censored na-GICs often intersect.

Although the comparison between these growth spells remains quite inconclusive when Proposition 1 is tested, some interesting features emerge from Figure 3. First, the censored na-GIC tends to 0 only at the highest part of the distribution for the three growth spells, according to both approaches (ex ante and ex post). This implies that only the richest individuals, belonging to the top $5 \%$ of the distribution, never experienced poverty. Interestingly, for a given approach the censored na-GICs of each growth episode have a similar shape, whereas the curve of the same growth episode shows a different trend if ex ante and ex post approaches are compared. The expected shape of standard na-GICs plotted according to the final ranking has a positive slope, with the final losers of growth growing 

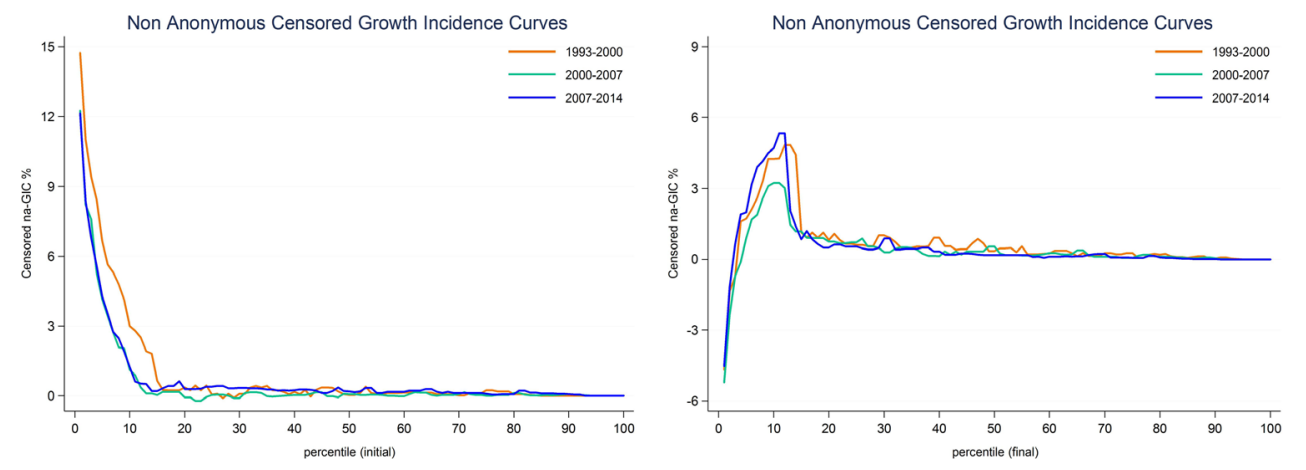

Figure 3. Proposition 1, condition (i) on the left and (ii) on the right Source: Authors' elaboration based on IFLS1, IFLS2, IFLS3, IFLS4 and IFLS5

less than the final gainers. This is indeed what we also find when we plot the standard na-GICs (see Figure 1). However, the censored na-GICs are characterized in the ex post approach by an inverted U-shape at the lower part of the distribution of income. To interpret this shape, one needs to keep in mind that, for the chronically poor (who allegedly are located in the bottom $10 \%$ of the final distribution), individual rates of growth are calculated by using expenditure at the beginning and at the end of the period. This can explain the increasing trend up to the 10th percentile. For the individuals who moved into poverty, instead the censored na-GICs are measured as deviations of current expenditure from the poverty line in the previous period. Therefore, these deviations might be relatively small for those individuals located in the lower-middle part of the distribution (10th-16th percentile) who were just above the poverty line in the first period. Analogously, in the middle part of the final distribution, we are likely to observe individuals who were never poor (those whose growth is censored to zero) as well as individuals who were just below the poverty line in the first period and experienced only small income changes, but enough to let them exit poverty. Zooming in on the bottom part of the distribution, when the ex ante approach is considered, the 1993-2000 period clearly dominates the other processes for the initially poorest $16 \%$, for whom, instead, the 2000-07 and 2007-14 periods seem to have almost identical impact. For the individuals initially ranked between the bottom $16 \%$ and the bottom $40 \%$, the 2007-14 curve lies almost always above the others (Figure D1 in Appendix D). When the ex post approach is adopted, the situation is almost reverted, although the dominances are less clear-cut. When the two approaches are considered at the same time, the 2000-07 growth period is shown to be the weakest: it is almost always dominated by the other growth periods.

When we allow for our dominances to be consistent with the smallest set of SEFs, we can compare the growth periods in question by resorting to the test provided in Proposition 2 and reported in Figure 4.

Figure 4 is quite informative, as it shows that two dominances can be proved: the dominance of the first and final growth periods over the second, which is confirmed to be the least pro-poor, with the gap between the processes being highest around the bottom $20 \%$. No dominance, instead, can be established between the first and final period. These results are robust to whether we opt for an ex ante or an ex post approach. If we are only in favour of the ex ante approach, then a clear and complete ranking can be defined 

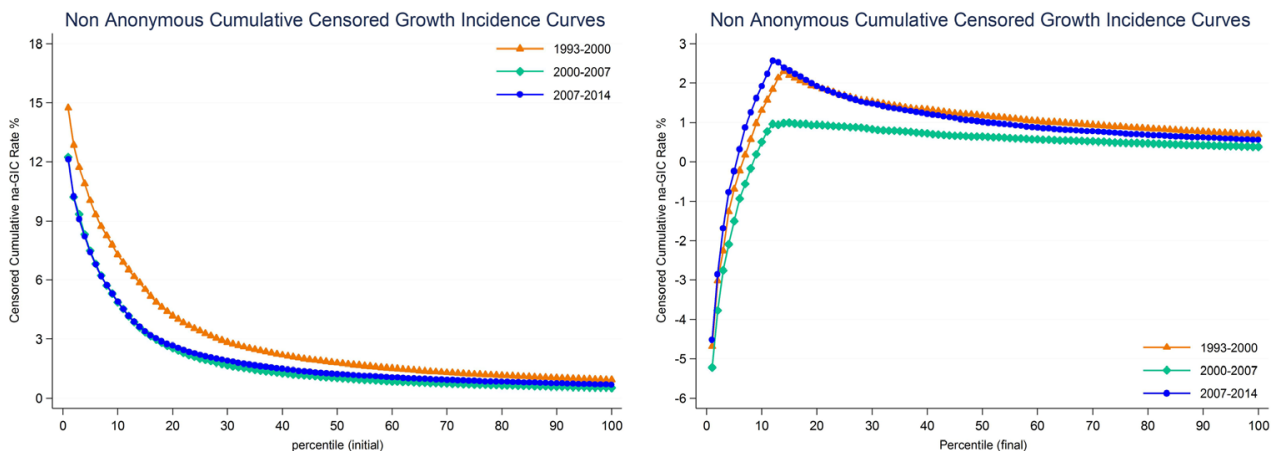

Figure 4. Proposition 2, condition (i) on the left and (ii) on the right Source: Authors' elaboration based on IFLS1, IFLS2, IFLS3, IFLS4 and IFLS5

with the first period dominating the second and with the first and second growth episodes dominating the most recent growth episode.

It is worth noting that it does make a difference in this ranking whether one is concerned with censored or standard na-GICs (see Figures 1 and 2). When censored na-GICs are adopted, no dominance holds between the second and third periods-according to the ex ante approach - and between the first and last periods - according to the ex post approach. This implies that there has been a difference in the impact of growth on each individual income with respect to the impact of the same growth on the poverty status of each individual.

Another interesting difference is that while with the adoption of the standard na-GICs the distance between the curves stays constant across the distribution, with the adoption of the censored na-GICs the distance between the curves is maximized around the lower-middle part of the distribution, tending to cancel out at the bottom and top of the distribution.

The last two partial orders between growth periods that we test are those characterized in Propositions 3 and 4. Recall that condition (i) of Proposition 3 is equivalent to condition (i) of Proposition 2 and is reported on the right of Figure 4, while condition (i) of Proposition 4 is equivalent to condition (ii) of Proposition 2 and is reported on the left of Figure 4. Condition (ii) of Proposition 3 is equivalent to condition (ii) of Proposition 4 and the result of its test is reported in Figure 5. Proposition 3 is more sensitive to the distribution of growth among individuals identified on the base of the rank in the initial distribution of income. Both conditions of Proposition 3 lead to the definition of the 1993-2000 growth period as superior to the subsequent two: $2000-07$ and 2007-14. Proposition 4 is more sensitive to the distribution of growth among individuals identified on the base of the rank in the final distribution of income.

Overall, the dominance of the first growth episode (1993-2000) over the last one (200714) appears to be quite robust, while the dominance between the first and second growth periods and between the second and the third does not always hold and the order of the ranking depends on the approach one uses.

It is also important to emphasize that it does make a difference in the ranking of the different growth periods whether one is concerned only with the initial status of individuals or only with their status of individuals in the final distribution. When the focus is on relative growth, conditions (i) and (ii) of Proposition 2 provide different results. In particular, when 


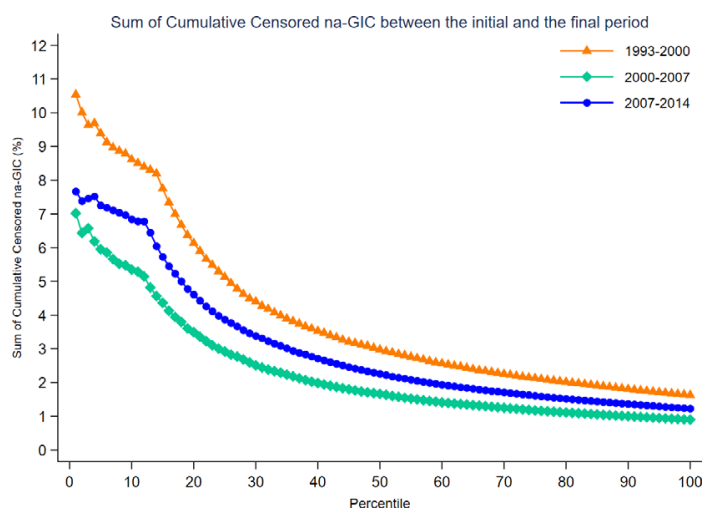

Figure 5. Proposition 3 and 4, condition (ii)

Source: Authors' elaboration based on IFLS1, IFLS2, IFLS3, IFLS4 and IFLS5

TABLE 1

\begin{tabular}{llll}
\multicolumn{4}{c}{ Aggregate indices } \\
\hline & $\bar{W}\left(G^{(t, t+1)}\right)$ & $\bar{W}\left(G^{(t, t+1)}\right)$ & $\bar{W}\left(G^{(t, t+1)}\right)$ \\
& $\omega_{t}=\omega_{t+1}=2$ & $\omega_{t}=3 ; \omega_{t+1}=2$ & $\omega_{t}=2 ; \omega_{t+1}=3$ \\
\hline $1993-2000$ & 1.33 & 1.67 & 1.43 \\
$2000-07$ & 0.77 & 0.98 & 0.81 \\
$2007-14$ & 1.02 & 1.23 & 1.13 \\
\hline
\end{tabular}

Source: Authors' elaboration based on IFLS1, IFLS2, IFLS3, IFLS4 and IFLS5.

only the status in the first period matters (condition (i)), it turns out that we obtain a clear ranking of the 1993-2000 growth process over the others that cannot be established when only the status in the final period matters (condition (ii)). By contrast, when only the second-period status matters (condition (ii)), the 2007-14 period dominates the 2000-07 period, but this dominance does not hold when the initial status is considered.

A complete ranking of the three growth spells analysed can instead be obtained by making use of the aggregate indices proposed in the previous section. The numerical value of these indices is reported in Table 1 and is quite robust to the choice of the parameter $\omega$ adopted. In particular, the 1993-2000 growth period is shown to be the best-performing period; it dominates the two subsequent periods. The 2000-07 period is shown to be the worst-performing as it is dominated by the other two growth periods.

The robust dominance of the first period can be interpreted in light of the development path followed by this country during the Suharto regime. In the early 1990s, Indonesia was indeed one of the key players in the so-called 'Asian miracle'. Similarly to other countries in the region, stable macroeconomic conditions, a booming export economy, and high-quality human capital favoured a sustained pattern of high economic growth. Differently from most of the neighbouring countries, this rapid economic development brought massive poverty reductions which - as already pointed out by many scholars (see inter alia Bolt et al., 2018; Timmer, 2018) - led to the 1990s being one of the most pro-poor growth episodes in modern economic history. In 1998, the country was hard-hit by the Asian Financial Crisis and recorded in that year a negative GDP growth rate of about $-13.7 \%$ (World Bank, 2001). 

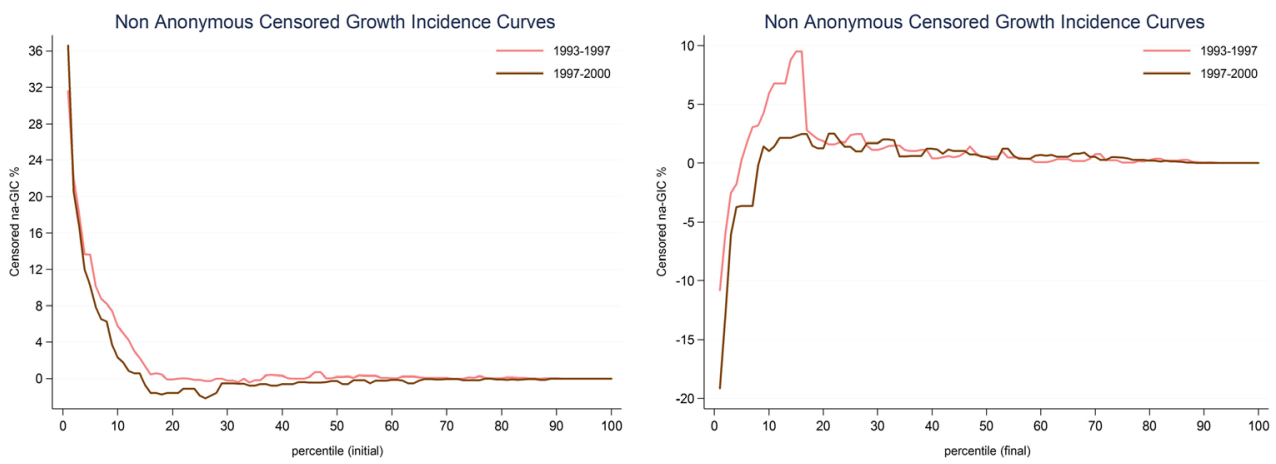

Figure 6. Non-anonymous GICs: ex ante (left) and ex post (right) approaches; 1993-97 vs 1997-2000 Source: Authors' elaboration based on IFLS1, IFLS2 and IFLS3
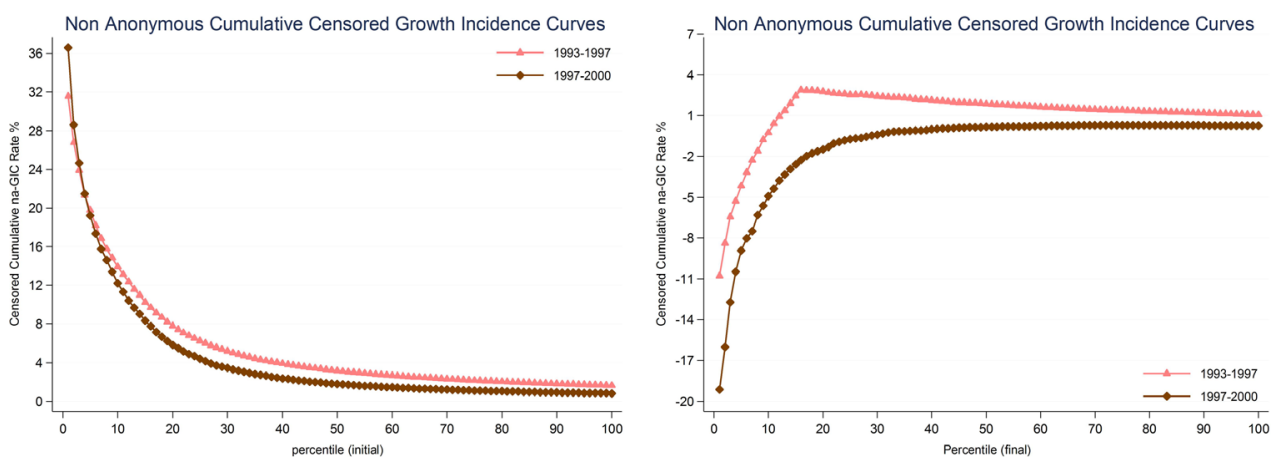

Figure 7. Cumulative non-anonymous GICs: ex ante (left) and ex post (right) approaches; 1993-97 vs 1997-2000

Source: Authors' elaboration based on IFLS1, IFLS2 and IFLS3

However, as was the case of most of the East Asian economies affected by the crisis, this sharp contraction was followed by a rapid return to growth (so-called 'V-shaped recovery'; World Bank, 2001) and the GDP per capita reverted its trend by increasing up to $3 \%$ in 2000. This implies that the performance of the 1993-2000 period shown in our analysis was mostly due to the growth experienced in the first part of this period (Figures 6 and 7).

The difference between the 1993-97 and the 1997-2000 periods is particularly evident by looking at the final losers of growth (the bottom $20 \%$ of the final distribution) in the ex post approach (Figures D2 and D3 in Appendix D). Here, as expected, the latter period is clearly - and to a large extent - dominated by the first one.

In the early 2000 s, the Indonesian economy continued to grow on average by $3.31 \%$ per year. Nevertheless, as our analysis shows, when the disaggregated and non-anonymous impact of growth matters, this fast recovery was not enough in terms of pro-poorness, as the 2000-07 period in most of the cases does worse than the previous period. This finding can be related to the conjuncture of the early 2000 s oil price shocks, the first attempts towards fuel subsidy reforms, and to the failure of some of the first welfare programmes that the government implemented to adequately compensate the poor for the increases in their 
living costs. ${ }^{9}$ As remarked by the World Bank, for example, governmental spending for pro-poor policies like rice-subsidization and other health and education interventions was not sufficiently high during these years (Bacon and Kojima, 2006). ${ }^{10}$ Another remarkable adjustment in petroleum product prices occurred in 2008. However, as also implied in our findings, poverty was not as significantly affected as in the earlier period. Compensation and stabilization price policies had indeed been more effective as a safety net for the poor. Moreover, Indonesia has suffered a relatively mild impact from the 2008 global financial crisis. Between 2008 and 2010, the economy was still growing at around 4\% per year (Thee, 2012) and it continued to grow at higher rates afterwards.

However, over the last 15 years reductions in vulnerability to poverty have been relatively small. From 2006 to 2014, according to a recent World Bank study (World Bank, 2016) the share of those vulnerable to poverty has decreased by about $2 \%$ points. ${ }^{11}$ At the same time, an 'emerging consumer class' lying in between the vulnerable and the economically secure has been growing since the early 2000 s at an annual rate of around $2.4 \%$. The World Bank's finding echoes two key results of our study: the high degree of mobility in and out of poverty in the lower-middle part of the 2007 distribution (Figure 3, left panel) and the clear dominance (Figure 8 in Appendix D, right panel) of the 1993-2000 period over the two most recent (and equally performing) periods for the effect of growth on the initially poor.

\section{Robustness check to measurement error}

The non-anonymous growth incidence curve (na-GIC), which is based on a joint income distribution, might be indeed the result of (non-classical) measurement error, generating a spurious relation between the base year reported income and the associated income change. Before checking the robustness of our results to measurement error, a consideration is in order: our main focus is the comparisons of non-anonymous growth processes over time. Hence, given that there have not been considerable changes in the design of the IFLS in the years considered, a bias in the extent of non-anonymous growth may be consistent with no bias in the estimated difference between two growth processes.

To analyse to what extent the pattern of our na-GICs is the result of measurement error, we adopt the approach suggested by Fields et al. (2003) and applied in the context of the na-GICs by Grimm (2007). Fields et al, 2003 proposed a test aimed at identifying the minimum level of measurement error which invalidates the relationship between the base year reported income and the income change. This is given by the ratio of the minimum amount of the variance of stochastic measurement error relative to the variance of true income that would be required to overturn the observed pattern of convergence. If this ratio

\footnotetext{
${ }^{9}$ As documented by the World Bank (Bacon and Kojima, 2006), between 2001 and 2003 the Indonesian government engaged in substantial fuel subsidy reform that resulted in a number of increases in the prices of several petroleum products that ultimately hit the poor.

${ }^{10}$ In 2005 the government started to implement an unconditional cash transfer programme (Bantuan Langsun Tunai, BLT); however, the literature on the effectiveness of the first edition of this programme does not come to uniform conclusions and, while some studies point to low mistargeting rates, others (e.g. Yusuf, 2008) stress the under-compensation for the urban poor.

${ }^{11}$ Vulnerability to poverty is defined in this study as those individuals having a greater than $10 \%$ chance of being poor the next year and being under 1.5 times the poverty line.
} 
is large enough to exceed a critical threshold, the estimated na-GIC (and the associated negative and positive slopes observed in the ex ante and ex post approach respectively) can be evaluated as robust against measurement error. By relying on two validation studies based on U.S. data, Fields et al. (2003) conclude that a credible range for the critical threshold of this ratio is equal to about 0.1 to 0.3 . We computed therefore, for each of the three periods analysed, this minimum threshold for different combinations of the serial correlation coefficient $\rho$ (as measurement errors may be correlated over time) and the correlation between base year expenditure and measurement error $\delta$ (as in Fields et al, 2003 and in Grimm, 2007). As the results suggest (see Table E1 in Appendix E), the estimates of the first period are moderately robust to measurement error. The estimated ratio in this period (which - in percentage terms - ranges from 14\% to 52\%) is indeed relatively close to the critical threshold so that measurement error could partly explain the observed estimates of convergence in the period 1993-2000. The estimates are much more robust for the last two periods. In particular, for the second period, for most of the combinations of $\rho$ and $\delta$, we observe that the ratio is quite high (above 0.6 and up to 1.06). In the the third period (2007-14), we observe that for two thirds of the combinations of $\rho$ and $\delta$, the ratio is above 0.3 . Thus, we can conclude that the measurement error characterizing the data we employ is not so quantitatively important as to reverse the conclusion of our analysis.

\section{Conclusions}

The macroeconomic events that have been experienced worldwide have motivated the elaboration of alternative models to evaluate growth according to each specific facet that may affect the distribution. In this paper, we have built a model to evaluate growth that focuses on its impact on the poverty dynamics of each individual and that is robust to the choice of the reference period used to identify individuals.

It is worth noting that pro-poor growth evaluations-performed using the censored naGIC-differ from growth evaluations-performed using the standard na-GIC-in one fundamental element: the presence of a poverty line. Differently from the evaluation of the dynamics of income distributions, where these distributions are unbounded, the evaluation of growth pro-poorness requires working with bounded distributions. This process creates two reference points; in addition to the income, we have the poverty line. Hence, it is possible to generate a normative framework for the evaluation of distributional dynamics in which comparisons are made taking distances from the latter and not only from the former to be ethically relevant. This is the case of our model, which focuses upon poverty changes and not income changes. For individuals who are poor in both periods, the two procedures-namely censored and standard na-GIC-will coincide, but not for those who experience a fall into or an exit from poverty.

Moreover, note that our framework can be usefully adopted to evaluate the net distributional impact of tax-benefit systems or to evaluate the efficacy of anti-poverty policies. Standard procedures imply comparing poverty before and after the policy has been applied. However, this type of procedure, although satisfactory from a pure distributional perspective, can be unsatisfactory from a normative perspective as it ignores the poverty dynamics at the individual level. Our framework casts light on two specific aspects to be considered 
in the evaluation of growth: the identity of individuals and the reference period. There are many other aspects that necessitate a deeper thinking and that might require the extension of these results in a number of directions. For instance, the framework proposed in this paper could be extended to endorse an intertemporal perspective that does not simply compare in a non-anonymous fashion the initial and the final periods, but is able to account for the income and status variation of individuals between these two periods. These extensions will be the subjects of future research.

\section{Appendix A: Proofs}

Proof of Proposition 1. We want to find sufficient and necessary conditions such that

$$
\begin{aligned}
\Delta \hat{W}= & \frac{1}{T} \sum_{t=1}^{T}\left(\int_{0}^{1} v\left(p_{t}\right)\left(\delta_{A}\left(p_{t}\right) d p_{t}-\delta_{B}\left(p_{t}\right) d p_{t}\right)+\right. \\
& \left.\int_{0}^{1} v\left(p_{t+1}\right)\left(\delta_{A}\left(p_{t+1}\right) d p_{t+1}-\delta_{B}\left(p_{t+1}\right) d p_{t+1}\right)\right) \geqslant 0, \text { for all } \hat{W} \in \hat{\mathbf{W}}_{1}, T=2
\end{aligned}
$$

Letting $\Delta \delta\left(p_{t}\right) d p_{t}=\delta_{A}\left(p_{t}\right) d p_{t}-\delta_{B}\left(p_{t}\right) d p_{t}$ and $\Delta \delta\left(p_{t+1}\right) d p_{t+1}=\delta_{A}\left(p_{t+1}\right) d p_{t+1}-\delta_{B}\left(p_{t+1}\right)$ $d p_{t+1}$, rewrite equation (15) as follows:

$$
\Delta \hat{W}=\frac{1}{T}\left(\int_{0}^{1} v\left(p_{t}\right) \Delta \delta\left(p_{t}\right) d p_{t}+\int_{0}^{1} v\left(p_{t+1}\right) \Delta \delta\left(p_{t+1}\right) d p_{t+1}\right) \geqslant 0
$$

For the sufficiency part, by Property $1 v\left(p_{t}\right), v\left(p_{t+1}\right) \geqslant 0$ for all $p_{t}, p_{t+1} \in[0,1]$, then $\Delta \delta\left(p_{t}\right) \geqslant$ 0 for all $p_{t} \in[0,1]$ and $\Delta \delta\left(p_{t+1}\right) \geqslant 0$ for all $p_{t+1} \in[0,1]$ imply $\int_{0}^{1} v\left(p_{t}\right) \Delta \delta\left(p_{t}\right) \geqslant 0$ and $\int_{0}^{1} v\left(p_{t+1}\right) \Delta \delta\left(p_{t+1}\right) \geqslant 0$, which imply $\Delta \hat{W} \geqslant 0$.

For the necessity part, let $\Delta \hat{W} \geqslant 0$, but assume that $\Delta \delta\left(p_{t}\right)<0$ for some $p_{t} \in[0,1]$ and that $\Delta \delta\left(p_{t+1}\right)<0$ for some $p_{t+1} \in[0,1]$. Following Lemma 1 in Chambaz and Maurin (1998), there exists a set of values $z(p) \in V^{+}$and $\rho(p) \in V^{+}$such that $\int_{0}^{1} z(p) \Delta \delta\left(p_{t}\right) d p_{t} \leqslant 0$ and $\int_{0}^{1} \rho(p) \Delta \delta\left(p_{t+1}\right) d p_{t+1} \leqslant 0$. Define $z(p)=v\left(p_{t}\right)$ and $\rho(p)=v\left(p_{t+1}\right)$, since $z(p), \rho(p) \in V^{+}$they satisfy Property 1 , now substituting in equation (15) gives $\Delta \hat{W} \leqslant 0$, which is a contradiction.

Proof of Proposition 2. We want to find sufficient and necessary conditions such that

$$
\Delta \hat{W}=\frac{1}{T}\left(\int_{0}^{1} v\left(p_{t}\right) \Delta \delta\left(p_{t}\right) d p_{t}+\int_{0}^{1} v\left(p_{t+1}\right) \Delta \delta\left(p_{t+1}\right) d p_{t+1}\right) \geqslant 0, \text { for all } \hat{W} \in \hat{\mathbf{W}}_{1,2}, T=2
$$

For the sufficiency part, we integrate by parts equation (17):

$$
\begin{gathered}
v\left(p_{t}=1\right) \int_{0}^{1} \Delta \delta\left(p_{t}\right) d p_{t}-\int_{0}^{1} v^{\prime}\left(p_{t}\right) \int_{0}^{p_{t}} \Delta \delta\left(q_{t}\right) d q_{t}+ \\
v\left(p_{t+1}=1\right) \int_{0}^{1} \Delta \delta\left(p_{t+1}\right) d p_{t+1}-\int_{0}^{1} v^{\prime}\left(p_{t+1}\right) \int_{0}^{p_{t+1}} \Delta \delta\left(q_{t+1}\right) d q_{t+1}
\end{gathered}
$$


Since by Property $1 v\left(p_{t}=1\right), v\left(p_{t+1}=1\right) \geqslant 0$ for all $p_{t}, p_{t+1} \in[0,1], \int_{0}^{p_{t}} \Delta \delta\left(q_{t}\right) d q_{t} \geqslant 0$ for all $p_{t} \in[0,1]$ and $\int_{0}^{p_{t+1}} \Delta \delta\left(q_{t+1}\right) d q_{t+1} \geqslant 0$ for all $p_{t+1} \in[0,1]$ imply $v\left(p_{t}=1\right) \int_{0}^{1} \Delta \delta\left(p_{t}\right) d p_{t} \geqslant 0$ and $v\left(p_{t+1}=1\right) \int_{0}^{1} \Delta \delta\left(p_{t+1}\right) d p_{t+1} \geqslant 0$. Furthermore, by Property $2 v^{\prime}\left(p_{t}\right) \leqslant 0$ and $v^{\prime}\left(p_{t+1}\right) \leqslant 0$ for all $p_{t}, p_{t+1} \in[0,1]$, we have $\int_{0}^{1} v^{\prime}\left(p_{t}\right) \int_{0}^{p_{t}} \Delta \delta\left(q_{t}\right) d q_{t} \leqslant 0$ and $\int_{0}^{1} v^{\prime}\left(p_{t+1}\right) \int_{0}^{p_{t+1}} \Delta \delta\left(q_{t+1}\right) d q_{t+1}$ $\leqslant 0$. Thus, $\Delta \hat{W} \geqslant 0$.

For the necessity part, let $\Delta \hat{W} \geqslant 0$, but assume that $\int_{0}^{p_{t}} \Delta \delta\left(q_{t}\right) d q_{t}<0$ for some $p_{t} \in[0,1]$ and that $\int_{0}^{p_{t+1}} \Delta \delta\left(p_{t+1}\right) d p_{t+1}<0$ for some $p_{t+1} \in[0,1]$. Rewrite equation (18) as follows:

$$
\begin{gathered}
v\left(p_{t}=1\right) \int_{0}^{1} \Delta \delta\left(p_{t}\right) d p_{t}+\int_{0}^{1}-v^{\prime}\left(p_{t}\right) \int_{0}^{p_{t}} \Delta \delta\left(q_{t}\right) d q_{t}+ \\
v\left(p_{t+1}=1\right) \int_{0}^{1} \Delta \delta\left(p_{t+1}\right) d p_{t+1}+\int_{0}^{1}-v^{\prime}\left(p_{t+1}\right) \int_{0}^{p_{t+1}} \Delta \delta\left(q_{t+1}\right) d q_{t+1}
\end{gathered}
$$

Denote $-v^{\prime}\left(p_{t}\right)=\alpha(p)$ and $-v^{\prime}\left(p_{t+1}\right)=\beta(p)$. By Lemma 2 in Chambaz and Maurin (1998), $\int_{0}^{1} \alpha(p) \int_{0}^{p_{t}} \Delta \delta\left(q_{t}\right) d q_{t} \leqslant 0$ for all $\alpha(p) \in V^{+}$and $\int_{0}^{1} \beta(p) \int_{0}^{p_{t+1}} \Delta \delta\left(q_{t+1}\right) d q_{t+1} \leqslant 0$ for all $\beta(p) \in$ $V^{+}$. Hence, the second and fourth term of equation (19) must be negative. Then it is always possible to find combinations of $v\left(p_{t}\right), v\left(p_{t+1}\right)$ and $\Delta \delta\left(p_{t}\right), \Delta \delta\left(p_{t+1}\right)\left(v\left(p_{t=1}\right)=v\left(p_{t+1=1}\right)=0\right.$, for instance) such that

$$
\begin{gathered}
\left|v\left(p_{t}=1\right) \int_{0}^{1} \Delta \delta\left(p_{t}\right) d p_{t}+v\left(p_{t+1}=1\right) \int_{0}^{1} \Delta \delta\left(p_{t+1}\right) d p_{t+1}\right|< \\
\left|\int_{0}^{1}-v^{\prime}\left(p_{t}\right) \int_{0}^{p_{t}} \Delta \delta\left(q_{t}\right) d q_{t}+\int_{0}^{1}-v^{\prime}\left(p_{t+1}\right) \int_{0}^{p_{t+1}} \Delta \delta\left(q_{t+1}\right) d q_{t+1}\right|
\end{gathered}
$$

which results in $\Delta \hat{W}<0$, a contradiction.

Proof of Proposition 3. We want to find sufficient and necessary conditions such that

$$
\Delta \hat{W}=\frac{1}{T} \sum_{t=1}^{T} \int_{0}^{1} v\left(p_{t}\right) \Delta \delta\left(p_{t}\right) d p_{t} \geqslant 0, \text { for all } \hat{W} \in \hat{\mathbf{W}}_{1,3}, T=2
$$

Integrating by parts:

$$
\Delta \hat{W}=\frac{1}{T} \sum_{t=1}^{T}\left[v\left(p_{t}=1\right) \int_{0}^{1} \Delta \delta\left(p_{t}\right) d p_{t}-\int_{0}^{1} v^{\prime}\left(p_{t}\right) \int_{0}^{p} \Delta \delta\left(q_{t}\right) d q_{t} d p_{t}\right] \geqslant 0
$$

For sufficiency, rewriting as follows:

$$
\Delta \hat{W}=\frac{1}{T} \sum_{t=1}^{T}\left[v\left(p_{t}=1\right) \int_{0}^{1} \Delta \delta\left(p_{t}\right) d p_{t}\right]+\frac{1}{T}\left[\int_{0}^{1} \sum_{t=1}^{T}-v^{\prime}\left(p_{t}\right) \int_{0}^{p} \Delta \delta\left(q_{t}\right) d q_{t} d p_{t}\right] \geqslant 0
$$

By Property 3: $-v^{\prime}\left(p_{t}\right) \geqslant-v^{\prime}\left(p_{t+1}\right) \geqslant 0$. Applying the Abel's Lemma we get that, for $t=1,2, \int_{0}^{p} \Delta \delta\left(q_{1}\right) d q_{1} \geqslant 0 \forall p$ and $\sum_{t=1}^{2} \int_{0}^{p} \Delta \delta\left(q_{t}\right) d q_{t} \geqslant 0 \forall p$, are sufficient to get $\frac{1}{T}\left[\int_{0}^{1} \sum_{t=1}^{T}-v^{\prime}\left(p_{t}\right) \int_{0}^{p} \Delta \delta\left(q_{t}\right) d q_{t} d p_{t}\right] \geqslant 0$. 
Given that by Property $1, v\left(p_{t}=1\right)$ and $v\left(p_{t+1}=1\right) \geqslant 0$, the above conditions are also sufficient to get $\Delta \hat{W} \geqslant 0$.

For the necessity, assume for a contradiction that $\Delta \hat{W} \geqslant 0$ but that $\exists I \equiv[a, b] \subseteq[0,1]$ such that $\int_{0}^{p} \Delta \delta\left(q_{1}\right) d q_{1} \leqslant 0$ and $\sum_{t=1}^{T} \int_{0}^{p_{t}} \Delta \delta\left(q_{t}\right) d q_{t} \leqslant 0 \forall p_{t} \in I$. By Abel's Lemma we get $+\frac{1}{T}\left[\sum_{t=1}^{T}-v^{\prime}\left(p_{t}\right) \int_{0}^{p_{t}} \Delta \delta\left(q_{t}\right) d q_{t}\right] \leqslant 0$ for all $p_{t} \in I$.

Assume that $\int_{0}^{p} \Delta \delta\left(q_{t}\right) d q_{t}$ is sufficiently close to 0 for all $p_{t} \notin I, \Delta \hat{W}$ would reduce to $\frac{1}{T} \sum_{t=1}^{T} v\left(p_{1}\right) \int_{a}^{b} \Delta \delta\left(p_{t}\right) d p_{t}+\frac{1}{T}\left[\int_{a}^{b} \sum_{t=1}^{T}-v^{\prime}\left(p_{t}\right) \int_{0}^{p} \Delta \delta\left(q_{t}\right) d q_{t} d p_{t}\right] \leqslant 0$, a contradiction.

Proof of Proposition 4. Before proving this proposition we need to state and prove the following lemma.

Lemma 1. $\sum_{i=1}^{n} v_{i} w_{i} \geqslant 0$ for all sets of number $\left\{v_{i}\right\}$ such that $0 \leqslant v_{1} \ldots \leqslant v_{i} \leqslant v_{i+1}$ $\leqslant \ldots \leqslant v_{n}$ for all $i \in\{1, \ldots, n\}$, if and only if $\sum_{i=j}^{n} w_{i} \geqslant 0$ for each $j .{ }^{12}$

Proof. For the sufficiency, note that $\sum_{i=1}^{n} v_{i} w_{i}$ can be decomposed as $\sum_{i=1}^{n} v_{i} w_{i}=$ $v_{1} \sum_{i=1}^{n} w_{i}+\sum_{i=1}^{n-1}\left(v_{i+1}-v_{1}\right) \sum_{j=i}^{n} w_{j}=v_{1} \sum_{i=1}^{n} w_{i}+\left(v_{2}-v_{1}\right) \sum_{i=2}^{n} w_{i}+\left(v_{3}-v_{2}\right) \sum_{i=3}^{n}$ $w_{i}+\ldots+\left(v_{n-2}-v_{n-3}\right) \sum_{i=n-2}^{n} w_{i}+\left(v_{n-1}-v_{n-2}\right) \sum_{i=n-1}^{n} w_{1}+\left(v_{n}-v_{n-1}\right) w_{n}$. It is clear that $\sum_{i=j}^{n} w_{i} \geqslant 0$ for each $j$ for each $j$ implies $\sum_{i=1}^{n} v_{i} w_{i} \geqslant 0$.

As for the necessity part, suppose that $\sum_{i=1}^{n} v_{i} w_{i} \geqslant 0$ for all sets of numbers $\left\{v_{i}\right\}$ such that $0 \leqslant v_{1} \ldots \leqslant v_{i} \leqslant v_{i+1} \leqslant \ldots \leqslant v_{n}$, but $\exists j \in 1, \ldots, n$ such that $\sum_{i=j}^{n} w_{i}<0$, then consider what happens when $v(1) \searrow 0$ and $v_{i+1}-v_{i} \searrow 0$ for all $i \neq j: \sum_{i=1}^{n} v_{i} w_{i}=v_{1} \sum_{i=1}^{n} w_{i}+\sum_{i=1}^{n-1}\left(v_{i+1}-v_{1}\right)$ $\sum_{j=i}^{n} w_{j}<0$, which is a contradiction.

We want to find sufficient and necessary conditions such that

$$
\Delta \hat{W}=\frac{1}{T} \sum_{t=1}^{T} \int_{0}^{1} v\left(p_{t}\right) \Delta \delta\left(p_{t}\right) d p_{t} \geqslant 0, \text { for all } \hat{W} \in \hat{\mathbf{W}}_{1,4}, T=2
$$

Integrating by parts:

$$
\Delta \hat{W}=\frac{1}{T} \sum_{t=1}^{T}\left[v\left(p_{t}=1\right) \int_{0}^{1} \Delta \delta\left(p_{t}\right) d p_{t}-\int_{0}^{1} v^{\prime}\left(p_{t}\right) \int_{0}^{p} \Delta \delta\left(q_{t}\right) d q_{t} d p_{t}\right] \geqslant 0
$$

For sufficiency, rewriting as follows:

$$
\Delta \hat{W}=\frac{1}{T} \sum_{t=1}^{T}\left[v\left(p_{t}=1\right) \int_{0}^{1} \Delta \delta\left(p_{t}\right) d p_{t}\right]+\frac{1}{T}\left[\int_{0}^{1} \sum_{t=1}^{T}-v^{\prime}\left(p_{t}\right) \int_{0}^{p} \Delta \delta\left(q_{t}\right) d q_{t} d p_{t}\right] \geqslant 0
$$

By Property 4: $-v^{\prime}\left(p_{t+1}\right) \geqslant-v^{\prime}\left(p_{t}\right) \geqslant 0$. Applying the Abel's Lemma we get that, for $t=1,2, \int_{0}^{p} \Delta \delta\left(q_{2}\right) d q_{2} \geqslant 0 \forall p$ and $\sum_{t=1}^{2} \int_{0}^{p} \Delta \delta\left(q_{t}\right) d q_{t} \geqslant 0 \forall p$, are sufficient to get

$\frac{1}{T}\left[\int_{0}^{1} \sum_{t=1}^{T}-v^{\prime}\left(p_{t}\right) \int_{0}^{p} \Delta \delta\left(q_{t}\right) d q_{t} d p_{t}\right] \geqslant 0$. Given that by Property $1 v\left(p_{t}\right), v\left(p_{t+1}\right) \geqslant 0$, these conditions are also sufficient to get $\Delta \hat{W} \geqslant 0$.

\footnotetext{
${ }^{12}$ Note that this is different from the Abel's Lemma, which states that a sufficient condition for $\sum_{i=1}^{n} v_{i} w_{i} \geqslant 0$ for all sets of $\left\{v_{i}\right\}$ such that $v_{1} \ldots \geqslant v_{i} \geqslant v_{i+1} \geqslant \ldots \geqslant v_{n}$ is $\sum_{i=1}^{j} w_{i} \geqslant 0$ for each $j$.
} 
For the necessity, assume for a contradiction that $\Delta \hat{W} \geqslant 0$ but that $\exists I \equiv[a, b] \subseteq[0,1]$ such that $\int_{0}^{p} \Delta \delta\left(q_{2}\right) d q_{2} \leqslant 0$ and $\sum_{t=1}^{2} \int_{a}^{b} \Delta \delta\left(q_{t}\right) d q_{t} \leqslant 0 \forall p_{t} \in I$, by Lemma 1 this would result in $+\frac{1}{T}\left[\sum_{t=1}^{T}-v^{\prime}\left(p_{t}\right) \int_{a}^{b} \Delta \delta\left(q_{t}\right) d q_{t} d p_{t}\right] \leqslant 0$. It possible to choose

$+\frac{1}{T}\left[\int_{0}^{1} \sum_{t=1}^{T}-v^{\prime}\left(p_{t}\right) \int_{0}^{p} \Delta \delta\left(q_{t}\right) d q_{t} d p_{t}\right] \forall p_{t} \notin I$ sufficiently close to 0 to get $\Delta \hat{W}=\frac{1}{T} \sum_{t=1}^{T}$ $v\left(p_{1}\right) \int_{a}^{b} \Delta \delta\left(p_{t}\right) d p_{t}+\frac{1}{T}\left[\int_{a}^{b} \sum_{t=1}^{T}-v^{\prime}\left(p_{t}\right) \int_{0}^{p} \Delta \delta\left(q_{t}\right) d q_{t} d p_{t}\right] \leqslant 0$, a contradiction.

\section{Appendix B: Some generalizations}

The results characterized in section Results are based on the assumption that the individual poverty is measured through the poverty gap; although this is a largely agreed assumption, one might want to measure deprivation using other measures of individual poverty. To this end, let $\varphi(y(p), z)$ denote any poverty measure at the individual level, with the usual property that $\varphi(y(p), z)>0$ if $y(p)<z$ and $\varphi(y(p), z)=0$ if $y(p) \geqslant z$.

For Proposition 1, the conditions to be satisfied would be:

$\delta_{A}\left(\varphi\left(y\left(p_{t}\right), z\right) \geqslant \delta_{B}\left(\varphi\left(y\left(p_{t}\right), z\right)\right) \forall p_{t} \in[0,1]\right.$ and

$\delta_{A}\left(\varphi\left(y\left(p_{t+1}\right), z\right) \geqslant \delta_{B}\left(\varphi\left(y\left(p_{t+1}\right), z\right) \forall p_{t+1} \in[0,1]\right.\right.$.

The first condition can be interpreted as the dominance between two 'pro-poor growth curves'. A pro-poor growth curve can be defined as a curve plotting against each individual the extent of poverty reduction experienced by this individual, with individuals sorted according to their rank in the initial distribution. The curve is negative in the case of an increase in or fall into poverty; it is positive in the case of reduction in or exit from poverty. The second condition is identical to the first, except for the fact that the individuals are now ranked according to their position in the final distribution of income. Thus, if we want to compare two growth episodes according to their degree of pro-poorness, we need to compare the extent of poverty reduction at each point of the distribution.

For Proposition 2, the relevant test is represented by the following:

$\int_{0}^{p_{t}} \delta_{A}\left(\varphi\left(y\left(q_{t}\right), z\right)\right) d q_{t} \geqslant \int_{0}^{p_{t}} \delta_{B}\left(\varphi\left(y\left(q_{t}\right), z\right)\right) q t \forall p_{t} \in[0,1]$ and
$\int_{0}^{p_{t+1}} \delta_{A}\left(\varphi\left(y\left(q_{t+1}\right), z\right)\right) d p_{t+1} \geqslant \int_{0}^{p_{t+1}} \delta_{B}\left(\varphi\left(y\left(q_{t+1}\right), z\right)\right) d p_{t+1} \forall p_{t+1} \in[0,1]$.

In this case, we need to check the dominance between two cumulative pro-poor growth curves at every point of the distributions. The test needs to be executed with individuals sorted according to their position in the pre-growth distribution and with individuals sorted according to their position in the postgrowth distribution of income.

Following the same line of reasoning, for Proposition 3 we need to check:

$$
\begin{aligned}
& \int_{0}^{p_{t}} \delta_{A}\left(\varphi\left(y\left(q_{t}\right), z\right)\right) d q_{t} \geqslant \int_{0}^{p_{t}} \delta_{B}\left(\varphi\left(y\left(q_{t}\right), z\right)\right) q_{t} \forall p_{t} \in[0,1] \text { and } \\
& \sum_{t=1}^{T} \int_{0}^{p_{t}} \delta_{A}\left(\varphi\left(y\left(q_{t}\right), z\right)\right) d p_{t} \geqslant \sum_{t=1}^{T} \int_{0}^{p_{t}} \delta_{B}\left(\varphi\left(y\left(q_{t}\right), z\right)\right) d p_{t} \forall p_{t+1} \in[0,1] .
\end{aligned}
$$

The results proposed in Proposition 4 can be generalized as follows:

$$
\begin{aligned}
& \int_{0}^{p_{t+1}} \delta_{A}\left(\varphi\left(y\left(q_{t+1}\right), z\right)\right) d q_{t+1} \geqslant \int_{0}^{p_{t+1}} \delta_{B}\left(\varphi\left(y\left(q_{t+1}\right), z\right)\right) q_{t+1} \forall p_{t+1} \in[0,1] \text { and } \\
& \sum_{t=1}^{T} \int_{0}^{p_{t}} \delta_{A}\left(\varphi\left(y\left(q_{t}\right), z\right)\right) d p_{t} \geqslant \sum_{t=1}^{T} \int_{0}^{p_{t}} \delta_{B}\left(\varphi\left(y\left(q_{t}\right), z\right)\right) d p_{t} \forall p_{t+1} \in[0,1] .
\end{aligned}
$$

The generalizations of Propositions 3 and 4 are sequential dominances of the second order to be checked on pro-poor growth curves. For Proposition 3, the first step requires 
checking dominance of the cumulative pro-poor growth curve at every percentile of the initial distribution, with individuals sorted on the basis of the first-period distribution. In the second step, we have to sum the cumulative pro-poor growth curve computed on individuals sorted according to their rank in the final period distribution. Reverting the reasoning for Proposition 4, we need to start from the cumulative pro-poor growth curve with individuals ordered on the basis of the final distribution of income and then summing at each percentile the cumulative pro-poor growth curve with individuals ordered on the basis of the final distribution of income.

\section{Appendix C: Descriptive Statistics}

TABLE C1

Descriptive statistics

\begin{tabular}{llll}
\hline & $1993-2000$ & $2000-07$ & $2007-14$ \\
\hline Mean monthly per capita expenditure, real RP (initial) & 311,479 & 415,931 & 510,551 \\
Mean monthly per capita expenditure, real RP (final) & 443,611 & 515,892 & 704,051 \\
Mean growth rate (annualized) & $5.46 \%$ & $3.14 \%$ & $5.24 \%$ \\
Individuals transitioning into poverty & $7.4 \%$ & $7.0 \%$ & $7.6 \%$ \\
Individuals moving out of poverty & $9.0 \%$ & $8.3 \%$ & $7.5 \%$ \\
Chronically poor & $5.0 \%$ & $4.1 \%$ & $3.8 \%$ \\
Poverty line, 50\% of the median, real RP (initial) & 114,796 & 155,340 & 194,813 \\
Poverty line, 50\% of the median, real RP (final) & 159,667 & 195,357 & 278,922 \\
Observations & 19,702 & 23,929 & 25,472 \\
\hline
\end{tabular}

Source: Authors' elaboration based on IFLS1, IFLS2, IFLS3, IFLS4 and IFLS5.

\section{Appendix D: Additional Figures}
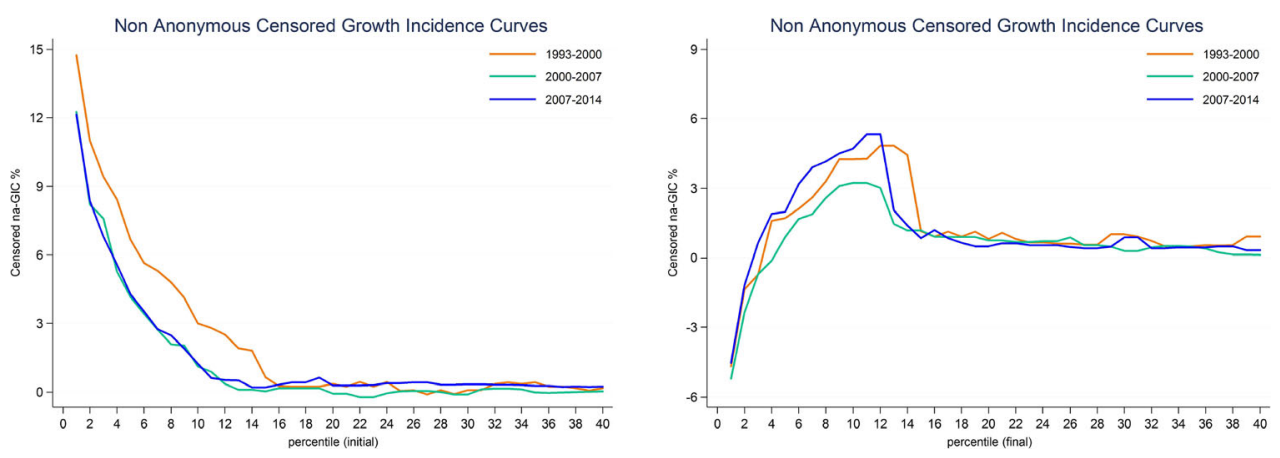

Figure D1. Proposition 1 up to to 40th percentile, condition (i) on the left and (ii) on the right Source: Authors' elaboration based on IFLS1, IFLS2, IFLS3, IFLS4 and IFLS5 

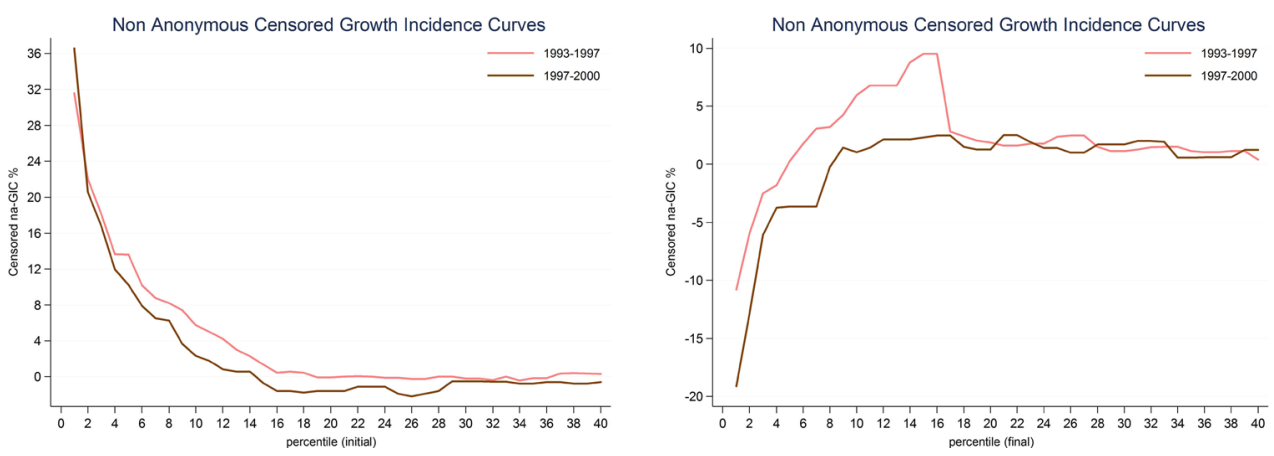

Figure D2. Proposition 1 up to to 40th percentile, condition (i) on the left and (ii) on the right, 1993-97 vs 1997-00

Source: Authors' elaboration based on IFLS1, IFLS2 and IFLS3
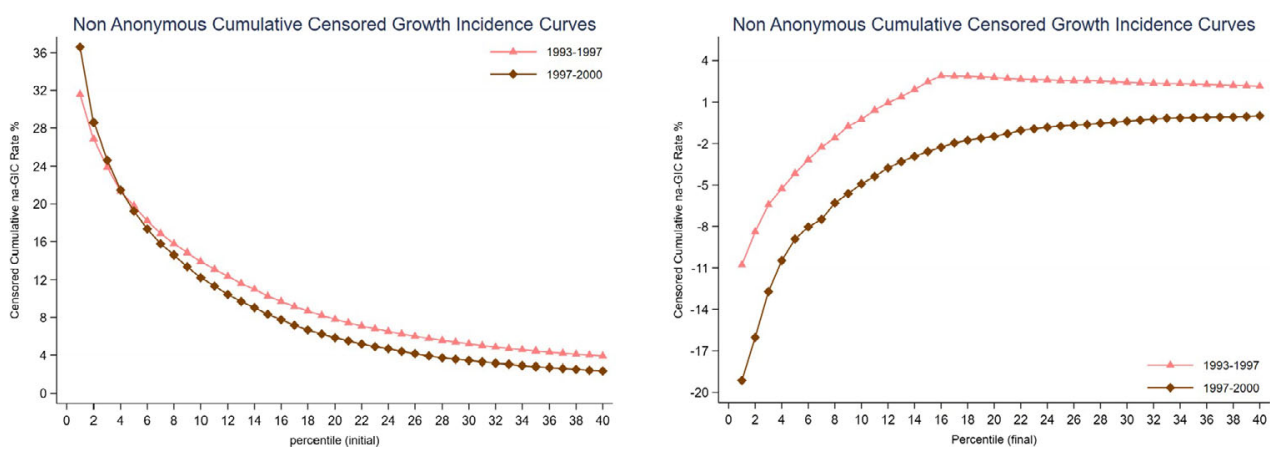

Figure D3. Proposition 2 up to to 40th percentile, condition (i) on the left and (ii) on the right, 1993-97 vs 1997-00

Source: Authors' elaboration based on IFLS1, IFLS2 and IFLS3 


\section{Appendix E: Measurement error}

\section{TABLE E1}

Ratio of measurement error to true income variance implying zero correlation between true initial income and true income change

\begin{tabular}{lllll}
\hline & & $\begin{array}{l}1993-2000 \\
\beta=-0,273\end{array}$ & $\begin{array}{l}2000-07 \\
\beta=-0,412\end{array}$ & $\begin{array}{l}2007-14 \\
\beta=-0,308\end{array}$ \\
\hline 0 & 0 & 0,376 & 0,700 & 0,445 \\
0 & 0,1 & 0,436 & 0,844 & 0,520 \\
0 & 0,2 & 0,519 & 1,061 & 0,626 \\
$-0,1$ & 0 & 0,305 & 0,567 & 0,361 \\
$-0,1$ & 0,1 & 0,353 & 0,683 & 0,422 \\
$-0,1$ & 0,2 & 0,420 & 0,859 & 0,507 \\
$-0,2$ & 0 & 0,241 & 0,448 & 0,285 \\
$-0,2$ & 0,1 & 0,279 & 0,540 & 0,333 \\
$-0,2$ & 0,2 & 0,332 & 0,679 & 0,401 \\
$-0,4$ & 0 & 0,135 & 0,252 & 0,160 \\
$-0,4$ & 0,1 & 0,157 & 0,304 & 0,187 \\
$-0,4$ & 0,2 & 0,187 & 0,382 & 0,225 \\
\hline
\end{tabular}

Source: Authors' elaboration based on IFLS1, IFLS2, IFLS3, IFLS4 and IFLS5.

Final Manuscript Received: January 2020.

\section{References}

Bacon, K. and Kojima, M. (2006). Coping with Higher Oil Prices. World Bank, Washington, DC.

Barcena, E. and Canto O. (2018). A Simple Subgroup Decomposable Measure of Downward (and Upward) Income mobility, Working Paper 2018/472. Palma de Mallorca: ECINEQ.

Benjamin, D., Brandt, L. and Giles, J. (2001). 'Did higher inequality impede growth in rural China?', Economic Journal, Vol. 121, pp. 1281-309.

Bolt, J., Inklaar, R., de Jong, H. and van Zanden, J. L. (2018). 'Rebasing 'Maddison': New Income Comparisons and the Shape of Long-Run Economic Development'. GGDC Research Memorandum 174. Groningen: Groningen Growth and Development Centre, University of Groningen.

Bourguignon, F. (2011). 'Non-anonymous growth incidence curves, income mobility and social welfare dominance', Journal of Economic Inequality, Vol. 9, pp. 605-27.

Bresson, F., Duclos, J.-Y. and Palmisano, F. (2019). 'Intertemporal pro-poorness', Social Choice and Welfare, Vol. 52, pp. 65-96.

Chambaz, C. and Maurin, E. (1998). 'Atkinson and Bourguignon's dominance criteria: extended and applied to the measurement of poverty in France', Review of Income and Wealth, Vol. 44, pp. 497-515.

Creedy, J. and N. Gemmell. (2018). 'Illustrating income mobility: new measures', Oxford Economic Papers, Vol. 71, pp. 733-755.

Donaldson, D. and J. Weymark. (1980). 'A single-parameter generalization of the gini indices of inequality', Journal of Economic Theory, Vol. 22, pp. 67-86.

Donaldson, D. and Weymark, J. (1983). 'Ethically flexible gini indices for income distributions in the continuum', Journal of Economic Theory, Vol. 29, pp. 353-358.

Duclos, J. (2009). 'What is “Pro-Poor"?', Social Choice and Welfare, Vol. 32, pp. 37-58. 
Essama-Nssah, B. (2005). 'A Unified framework for pro-poor growth analysis', Economics Letters, Vol. 89, pp. 216-21.

Essama-Nssah, B., and P. Lambert. (2009). 'Measuring pro-poorness: a unifying approach with new results', Review of Income and Wealth, Vol. 55, pp. 752-78.

Fields, G. S., Cichello, P. L., Freije, S., Menéndez, M. and Newhouse, D. (2003). 'For richer or for poorer? Evidence from Indonesia, South Africa, Spain, and Venezuela', The Journal of Economic Inequality, Vol. 1, pp. 67-99.

Foster, J. and Rothbaum, J. (2016). 'Uso de paneles sintéticos para estimar movilidad intergeneracional', Sobre México. Revista de Economía. Sobre México.Temas en economía, Vol. 2, pp. 62-89.

Grimm, M. (2007). 'Removing the anonymity axiom in assessing pro-poor growth', Journal of Economic Inequality, Vol. 5, pp. 179-97.

Hoy, M., and B. Zheng. (2011). 'Measuring lifetime poverty', Journal of Economic Theory, Vol. 146, pp. 2544-62.

Jenkins, S. and Van Kerm, P. (2016). 'Assessing individual income growth', Economica, Vol. 83, pp. 679-703.

Kraay, A. (2006). 'When is growth pro-poor? evidence from a panel of countries', Journal of Development Economics, Vol. 80, pp. 198-227.

Kuznets, S. (1955). 'Economic growth and income inequality', American Economic Review, Vol. 45, pp. 1-28.

Palmisano, F. (2018). 'Evaluating patterns of income growth when status matters: a robust approach', Review of Income and Wealth, Vol. 64, pp. 147-169.

Palmisano, F. and Peragine, V. (2015). 'The distributional incidence of growth: a social welfare approach', Review of Income and Wealth, Vol. 61, pp. 440-64.

Palmisano, F. and Van de Gaer, D. (2016). 'History dependent growth incidence: a characterization and an application to the economic crisis in Italy', Oxford Economic Papers, Vol. 68, pp. 585-603.

Ravallion, M. (1998). 'Does aggregation hide the harmful effect of inequality on growth?', Economic Letters, Vol. 61, pp. 73-77.

Ravallion, M. (2012). 'Why don’t we see poverty convergence?', American Economic Review, Vol. 102, pp. 504-23.

Ravallion, M. and Chen, S. (2003). 'Measuring pro-poor growth', Economics Letters, Vol. 78, pp. 93-99.

Ravallion, M. and Chen, S. (2007). 'China's (uneven) progress against poverty', Journal of Development Economics, Vol. 82, pp. 1-42.

Shorrocks, A. F. (1995). 'Revisiting the sen poverty index', Econometrica, Vol. 63, pp. 1225-1230.

Son, H. (2004). 'A note on pro-poor growth', Economics Letters, Vol. 82, pp. 307-14.

Strauss, J., Witoelar, F. and Sikoki, B. (2016). The Fifth Wave of the Indonesia Family Life Survey: Overview and Field Report, Vol. 1. RAND, Santa Monica, CA.

Thee, K. (2012). 'The impact of the global financial crisis on the indonesian economy and the prospects for the resumption of rapid and sustained growth'. In Indonesia's Economy since Independence. Singapore: ISEAS-Yusof Ishak Institute.

Timmer, C. P. (2018). Pro-Poor Growth in Indonesia: Challenging the Pessimism of Myrdal's Asian Drama. WIDER Working Paper 2018/103. Helsinki: UNU-WIDER.

Van Kerm, P. (2009). 'Income mobility profiles', Economic Letters, Vol. 102, pp. 93-95.

Weymark, J. (1981). 'Generalized gini inequality indices', Mathematical Social Sciences, Vol. 1, pp. 409-430.

World Bank (2001). Rethinking the East Asian Miracle. World Bank, Washington, DC.

World Bank (2016). Indonesia's Rising Divide. World Bank, Jakarta.

Yaari, M. (1988). 'A controversial proposal concerning inequality measurement', Journal of Economic Theory, Vol. 44, pp. 381-397.

Yitzhaki, S. (1983). 'On an extension of the gini index of inequality', International Economic Review, Vol. 24, pp. 617-28.

Yusuf, A. (2008). The Distributional Impact of Environmental Policy: The Case of Carbon Tax and Energy Pricing Reform in Indonesia. Research Report rr2008101. Laguna: Economy and Environment Program for Southeast Asia (EEPSEA).

Zheng, B. (1997). 'Aggregate poverty measures', Journal of Economic Surveys, Vol. 11, pp. 123-162. 